\title{
Environmental Toxicants Induced Male Reproductive Disorders: Identification and Mechanism of Action
}

\author{
Kuladip Jana and Parimal C. Sen \\ Division of Molecular Medicine, \\ Bose Institute, Kolkata, \\ India
}

"Several observations on poor trends in Male Reproductive Health have been reported during the last Decades. These difficult trends include the increasing prevalence of Testicular Cancer, Low and possibly declining Semen Quality, high and possibly rising frequencies of Cryptorchidism

(Undescended Testis) and malformation of the Penis (Hypospadias) as well as a increasing demand for Assisted Reproduction".

\section{Introduction}

The phrase 'endocrine disruption' has seemingly become inextricably linked with terms like 'environmental oestrogens' and 'falling sperm counts'. While these connections aid understanding about these issues, they represent a simplified view of the field of endocrine disruption. There is currently no strong data to suggest that environmental endocrine disrupters (EDCs) are responsible for the observed disintegration in human male reproductive health, but there are secular trends to suggest that it is declining. There is, however, very good evidence that lifestyle factors (e.g. smoking, alcohol consumption and/or use of cosmetics) can have an impact on fertility (Sharpe \& Franks 2002; Sharpe \& Irvine, 2004). Similarly, the notion that all EDCs act by mimicking oestrogen (environmental oestrogens) is too simplistic. The current literature illustrates that EDCs can act as oestrogens, anti-oestrogens, anti-androgens, steroidogenic enzyme inhibitors and can also act via interaction with the thyroid hormones and their receptors, or within the brain and the hypothalamo-pituitary axis, as well as the immune system (Fisher, 2004; Jana et al., 2006; 2010a). Reports of declining sperm counts over the past 50 years and other disturbing trends alerted scientists to the possibility that exposure to chemicals in the environment may damage male reproductive health (Carlsen et al., 1992). Testicular cancer, the most common malignancy in men 15-44 years of age, has increased markedly in incidence in this century in virtually all countries studied. The incidence of hypospadias, a developmental malformation of the male urethra, appears to be increasing worldwide. Cryptorchidism (undescended testicle), another developmental defect, may have increased in some human populations and appears to be increasing in wildlife (Toppari et al., 1996; Fisher, 2004, Sharpe, 2010). The causes of these trends have not been identified and relevant toxicological data about male reproductive effects of environmental toxicants are limited. Recent research efforts have 
focused on the possibility that exposures to hormonally active compounds, particularly during childhood and in utero, are to blame, at least in part, for changes in semen quality, increasing rates of testicular cancer, and malformations of the male urogenital tract (Sharpe, 2010). The ability to investigate environmental determinants of these indicators of male reproductive health is currently limited by available methodologies and data.

\subsection{The male reproductive system: Environmental influence}

Global changes in semen quality are suggested to be produced by the enhanced exposure to environmental chemicals contained in pesticides, food sources, cosmetics, plastics, electronics, and other synthetic materials (Carlsen et al., 1992). The biological basis for this hypothesis is the action of certain chemical compounds, both naturally occurring and anthropogenic (man-made), on endogenous hormone receptors and hormone-dependent pathways. These chemicals are termed hormonally active agents, environmental estrogens, hormone mimics, and endocrine disrupters/disruptors (US. EPA, 1998a; 1998b; National Research Council [NRC], 1989). A wide range of mechanisms of action are described for endocrine disrupters, including agonists of the estrogen receptor (ER) genistein, diethylstilbestrol (DES; Roy et al., 1997), and bisphenol A (BPA; Kuiper et al., 1998); androgen receptor (AR) antagonists such as vinclozolin (Wong et al., 1995), linuron, procymidone (Gray et al., 1999), phthalates (Foster et al., 2001), and p,p'-dichlorodiphenyl dichloroethylene ( $p, p^{\prime}$-DDE; Kelce et al., 1995) and aryl hydrocarbon receptor (AhR) agonists, which include dioxins (Toyoshiba et al., 2004), polychlorinated biphenyls (PCB), polycyclic aromatic hydrocarbons (PAH), and polychlorinated dibenzofurans (PCDF; Peterson et al., 1993). Exposure to endocrine-disrupting chemicals may occur through environmental routes (air, soil, water, food) or via occupational exposures (Figure 1) (Sharpe \& Irvine, 2004).

\subsection{The testis: Male reproductive organ}

The testis is both an endocrine gland and a reproductive organ, responsible for the production of hormones and male gametes and an important target for endocrine disruption. The testis consists of two types of tissues: seminiferous tubules, supported by Sertoli cells, and the interstitial compartment, comprised of Leydig cells (Fisher, 2004; Akingbemi, 2005). Testicular functions (spermatogenesis steroidogenesis) are regulated by the hypothalamic-pituitary-testicular (HPT) axis which involves the pituitary gonadotropins luteinizing hormone (LH) and follicle-stimulating hormone (FSH; Jana et al., 2006). Testicular functions are proposed to be regulated by a number of hormones and growth factors in addition to FSH, LH, and androgens, including insulin-like growth factor, oxytocin, and transforming growth factor- $\alpha$ and estrogens (Pryor et al., 2000).

\subsubsection{Spermatogenesis}

Spermatogenesis is the formation of the male gamete or spermatozoa. Spermatogenesis is dependent on the integrity of the architecture of the seminiferous tubules and Sertoli cells and endocrine regulation and is regulated by testosterone and FSH. In response to $\mathrm{LH}$, Leydig cells produce androgens, including testosterone, which along with FSH bind to their respective Sertoli cell receptors to regulate spermatogenesis. Spermatogenesis requires unique associations between Sertoli cells and developing male germ cells such that the seminiferous tubules are lined by Sertoli cells and joined by tight junctions forming the 


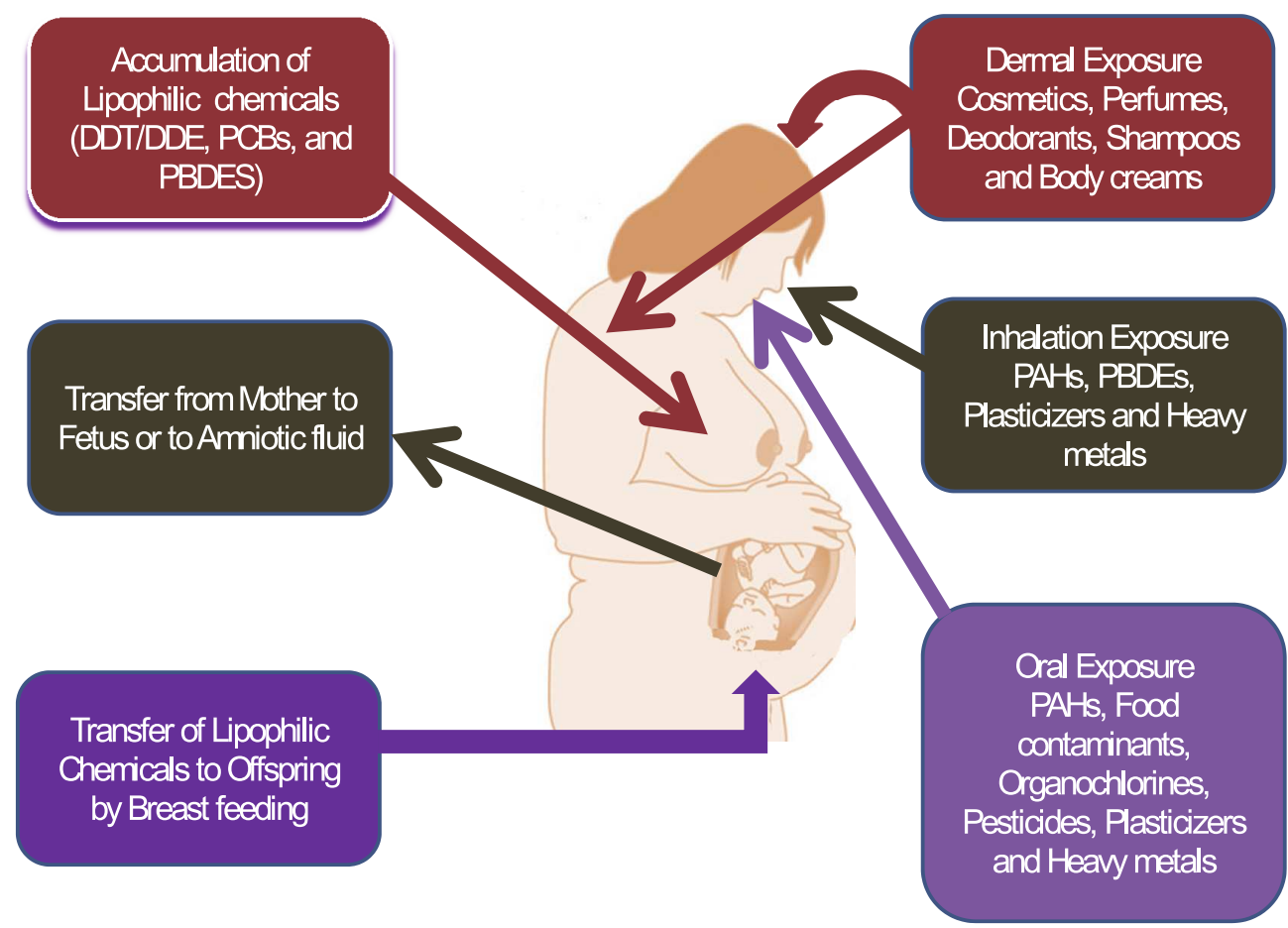

Fig. 1. Routes of human exposure to some common environmental chemicals. DDE=1,1dichloro-2, 2-bis ( $\mathrm{p}$ - chlorophenyl) ethylene; DDT= dichlorodiphenyltrichloroethane; $\mathrm{PAHs}=$ polycyclic aromatic hydrocarbons; $\mathrm{PCBs}=$ polychlorinated biphenyls. (Modified from Sharpe \& Irvine, BMJ, 2004).

blood-testis barrier (BTB; Walker \& Cheng, 2005). There are three major phases of spermatogenesis: (1) spermatogonial phase, (2) spermatocyte phase, and (3) spermatid phase (Figure 2). In the first phase the diploid spermatogonia undergo mitosis and create stem cells and diploid primary spermatocytes. During the second phase the primary spermatocytes undergo two rounds of meiosis, producing haploid spermatids. Finally, the spermatids begin a differentiation phase, sometimes referred to as spermiogenesis, during which the immature gametes develop into mature spermatozoa (O'Donnell et al., 2001). Spermatids continue their differentiation (spermiogenesis) while physically associated with the Sertoli cells. Spermiogenesis includes polarization of the spermatid, formation of the acrosome cap and flagellum, condensation, elongation of the nucleus, and cytoplasmic remodelling to produce the characteristic appearance of the mature spermatozoa. Spermatozoa are morphologically mature but immotile and are then released into the lumen of the seminiferous tubules (spermiation). At this stage these immotile testicular spermatozoa are not yet capable of fertilization (O'Donnell et al., 2001). The BTB between Sertoli cells comprises a co-existing tight junction (TJ), desmosome, gap junction and a testisspecific adherens junction (AJ) called the basal ectoplasmic specialization (ES). The basal ES is typified by the presence of actin filament bundles 'sandwiched' between the plasma membrane and the cisternae of endoplasmic reticulum in two neighbouring Sertoli cells. 
However, recent studies show that the unique structural aspects of the BTB, such as the presence of focal adhesion protein FAK, also render the testis highly susceptible to damage from environmental toxicants. Third, during spermiogenesis when round spermatids differentiate into elongated spermatids, genetic material in the spermatid head condense to form the tightly packed nucleus with the formation of an acrosome above the head region and elongation of the spermatid tail. During this time, spermatids migrate towards the adluminal compartment of the seminiferous tubule until elongated spermatids are released into the tubule lumen via the disassembly of another ES, the apical ES, at spermiation. The apical ES anchors developing spermatids in the seminiferous epithelium until they are fully developed. Thus, disruption of the apical ES (e.g. by environmental toxicants) causes the premature release of spermatids that are structurally defective (e.g. lack of acrosome and/or tail) and which are incapable of fertilizing the ovum (Wong \& Cheng, 2011).
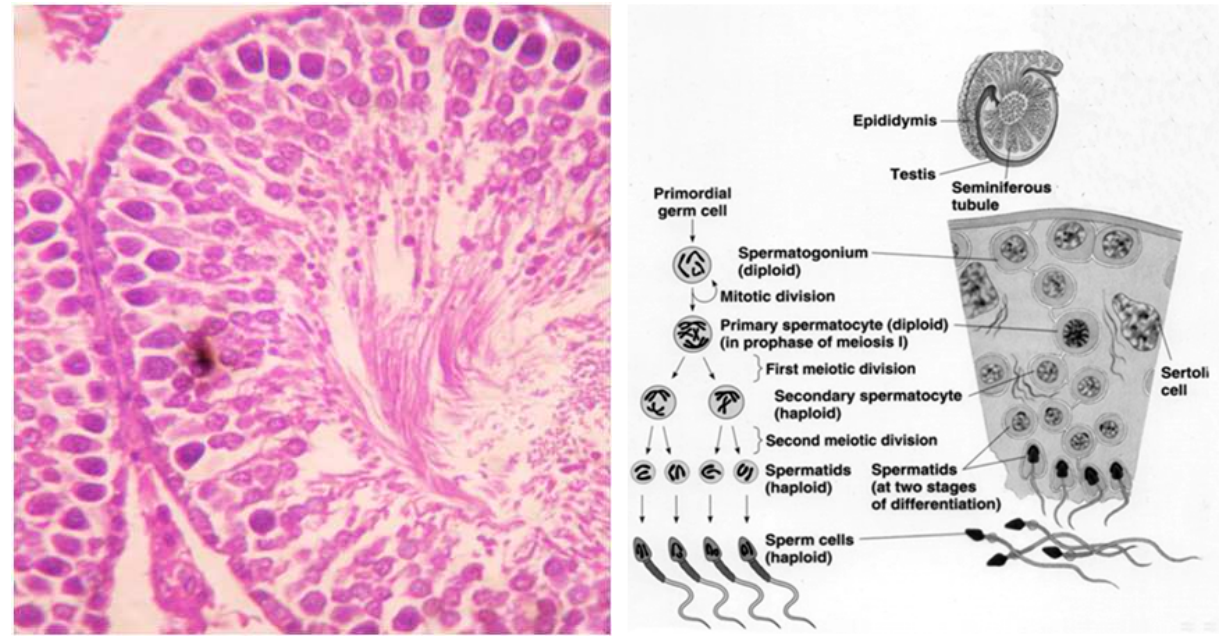

Fig. 2. The process of normal mammalian spermatogenesis with three major phases: (1) spermatogonial phase, (2) spermatocyte phase, and (3) spermatid phase.

\subsubsection{Sperm maturation}

The immotile spermatozoa are transported from the lumen of the seminiferous tubules by peristaltic contractions of adjacent myoid cells. The spermatozoa are suspended in a fluid secreted by Sertoli cells and migrate through a series of ductules within the testis (rete testis), passing through the efferent ductules and eventually entering the epididymis. The efferent ductules concentrate the spermatozoa by reabsorbing fluid (O'Donnell et al., 2001). There is evidence from transgenic mice that this fluid resorption is regulated by estrogen (Hess et al., 1997). The segments of the epididymis, caput, corpus, and cauda secrete proteins, and endocytose secreted proteins from the epididymal lumen to contribute to the maturation of the spermatozoa (O'Donnell et al., 2001). It is within the epididymis that the spermatozoa gain motility machinery. However, these spermatozoa remain immotile as they are pushed through the rest of the reproductive tissues via peristaltic contractions. It is during this final passage that seminal fluid is produced by the seminal vesicles, which contributes about $70 \%$ to the semen, and the prostate gland, which contributes another 10- 
$30 \%$. Seminal fluid is comprised of proteins, enzymes, fructose, mucus, vitamin-C, flavins, phosphorylcholine, and prostaglandins (Purvis et al., 1986). Decreases in seminal fluid volume may therefore indicate diminished seminal vesicle or prostate functions.

\subsection{The role of androgens in male reproductive tract development}

Male reproductive tract development is a dynamic process requiring the interaction of many factors and hormones. One of the major factors essential for the development of the male internal and external male reproductive tract are the androgens, testosterone and dihydrotestosterone (DHT) (Phillips \& Tanphaichitr, 2008). Androgens are produced by the testes during fetal and neonatal development and are essential for the maintenance of the Wolffian duct that differentiates into the epididymis, vas deferens and the seminal vesicles. The masculinization of these reproductive structures is mediated by testosterone. The masculinization of the external genitalia and prostate is largely mediated by DHT which is a more potent metabolite of testosterone and is produced by the action of the enzyme $5 \mathrm{a}-$ reductase. The central role of androgens in driving these developmental processes illustrates why chemicals that can interfere with the synthesis or action of androgens can have deleterious consequences for the developing male genital tract. Administration of the antiandrogen, flutamide (an androgen receptor antagonist), during male reproductive tract development resulted in abnormalities in the formation of the external genitalia hypospadias and cryptorchidism; internally, agenesis of the epididymis, vas deferens and prostate (Mylchreest et al., 2000). Within the testis, degeneration of the seminiferous epithelium and Leydig cell hyperplasia were common (although this may be a consequence of the cryptorchidism rather than an anti-androgenic effect). The male pups also displayed retained thoracic nipples and a reduced anogenital distance (feminised) which are both indicative of reduced androgen action in fetal life (Mylchreest et al., 2000). In summary, both testosterone- and DHT-mediated male reproductive tract development is impaired by flutamide when administered over the period of reproductive tract differentiation.

\subsection{Problems with male reproductive health \\ 1.4.1 Semen quality}

Reports suggesting that sperm counts have declined in certain areas of industrialized countries throughout the world have contributed to concern about a possible worldwide decline in human semen quality (Swan et al., 1997). A meta-analysis by Carlsen et al.,(1992) reported a worldwide decline in sperm counts over the preceding 50 years, concluding that mean sperm concentrations had decreased by almost 50\% from 1940 to 1990. Numerous researchers have attempted to determine whether this apparent decline is real or due to unrecognized biases in data collection and analysis. Confounding Variables may account for the observed findings. Potential confounders include increasing donor age, duration of abstinence, frequency of ejaculation, and even the season of sample collection, all of which influence sperm variables. Other suggested confounders include smoking, chemicals and radiation exposures, stress, ethnicity, and a variety of physical conditions including varicocele, infection, and genital abnormalities such as hypospadias and cryptorchidism. Theories explaining the apparent geographic disparities in sperm counts are currently only speculative, and include environmental, socioeconomic, racial, and methodologic differences (Swan et al., 1997). Fisch et al., (1996) reported yearly fluctuations in mean sperm counts and birth rates (Fisch et al., 1997), suggesting that this may be a more important variable than previously considered. 


\subsubsection{Testicular cancer}

Testicular cancer is often quoted as the commonest cancer of young men. The secular trends across Europe and the United States show that it is increasing in incidence in Caucasian men (SEER 2003). There is widespread geographical variation and the incidence of testicular cancer can vary up to 10-fold between countries. In Denmark in 1980, the age standardised incidence rate per 100000 population was $7.8 \%$ whereas in Lithuania it was $0.9 \%$, although in all countries where registry data has been analysed there was an annual increase of 2.3$3.4 \%$ (Adami et al., 1994). The increase in testicular cancer has been linked to a birth cohort effect, suggesting that factors affecting in utero development may be important (Bergstrom et al., 1996). Testicular germ cell cancer arises from cells which have similar characteristics to fetal germ-cells; these pre-malignant cells are termed carcinoma-in situ (CIS) cells (RajpertDe Meyts et al., 2003). How these cells persist during development and what causes them to proliferate after puberty is not well understood, although it is thought that the factors that promote normal germ cell division may also be important in promoting CIS proliferation. Abnormal intrauterine hormone levels i.e. decreased androgen and/or increased oestrogen levels are believed to be important in the occurrence of testicular cancer (Sharpe \& Skakkebaek 1993). Similarly, decreased androgen and/or increased oestrogen levels have also been implicated in the occurrence of cryptorchidism, hypospadias and low sperm counts (Sharpe \& Skakkebaek 1993). Although genetics almost certainly plays a major role in the etiology of the disease, other etiologies, including environmental factors, need to be elucidated to explain why, for example, major differences in testicular cancer rates exist among the relatively genetically homogenous Scandinavian countries. Increases in testicular cancer rates are not recent phenomena. A doubling in incidence was documented in Denmark within 25 years after the initiation of cancer registration in 1943 (Ekbom \& Akre, 1998). Mortality data from Great Britain show an increase in mortality due to testicular cancer beginning in the 1920s (Davies, 1981). These mortality data raise an important distinction: if environmental risk factors play a role in testicular cancer incidence, relevant exposures must therefore have existed since the turn of the century. This would make it less likely that organochlorines such as DDT and other endocrine-disrupting chemicals are possible etiologic agents. Research is ongoing to explore new genetic markers for early detection of carcinoma in situ cells in semen, as well as to define the role of hormonal assays (e.g., inhibin-B) as screening tools for testicular cancer and carcinoma in situ.

\subsubsection{Congenital abnormalities (Cryptorchidism and hypospadias)}

Cryptorchidism and hypospadias are abnormalities normally detected at birth (congenital abnormalities). Cryptorchidism occurs when the testis does not descend into the scrotal sac; this is generally unilateral but can be bilateral. Hypospadias is a developmental abnormality of the penis in which the urethral opening is not located at the tip of the glans penis but can occur anywhere along the shaft. Determining whether there is a real increase in hypospadias and/or cryptorchidism is confounded by changes in diagnostic criteria and recording practices which make the registry data unreliable (Toppari et al., 1996). Despite this, cryptorchidism is the most common congenital abnormality of the newborn (2-4\% incidence) and trends for hypospadias suggest a progressive increase; based on registry data, hypospadias is the second most common (0.3-0.7\% at birth) congenital malformation (Sharpe, 2003). Prospective studies are underway, which employ standardised diagnostic criteria, to collect robust data about the current incidence of cryptorchidism and 
hypospadias. This will allow the monitoring of future trends and allow international comparisons on the incidences of these disorders. However, two male genital birth defects, hypospadias and cryptorchidism, both apparently representing mild degrees of feminization, have become important in the ongoing debate regarding the significance of endocrine disruptors or other environmental influences on male development (Sharpe \& Skakkebaek, 1993). Several researchers have reported increases in each of these defects in the past three decades. To evaluate the hypothesis of common etiologies, pre- and peri-natal determinants of hypospadias, cryptorchidism, testicular cancer, and infertility are under investigation. Abnormal sex hormone exposure during critical periods of development has been postulated as a likely shared pathologic mechanism (Toppari et al., 1996).

\subsubsection{There is a link between these male reproductive health issues}

The strongest evidence suggesting a link between these male reproductive tract disorders, aside from the (largely imperfect) data which suggests they are all increasing in incidence, is the fact that epidemiologically the occurrence of one disorder is a risk factor for the occurrence of another (Skakkebaek et al., 2001, Sharpe, 2003). This has led to the proposal that low sperm counts, hypospadias, cryptorchidism and testicular germ cell cancer are interrelated disorders comprising a 'testicular dysgenesis syndrome' (TDS; Skakkebaek et al., 2001, Sharpe, 2003, 2010; Figure 3). The disorders that comprise TDS all have their roots in fetal development, suggesting that a possible causal link lies in abnormal hormone synthesis or action during reproductive tract development. From the historical literature, it is well known that the administration of diethylstilboestrol (DES; a potent synthetic oestrogen) to pregnant humans and rodents causes reproductive tract abnormalities in the offspring (Stillman, 1982). In male rodents, neonatal administration of DES induces a reduction in the number of Sertoli cells (the major somatic cell type which supports spermatogenesis) (Sharpe et al., 2003). There is also data suggesting DES administration to humans induces an increase in the incidence of cryptorchidism, although it is less certain whether hypospadias and testicular cancer show any significant increase (Stillman, 1982). DES only induces male reproductive tract abnormalities after administration at very high doses, which are probably not relevant to environmental considerations. However, what is of more concern is that, when administered at high doses, DES and other potent oestrogens are capable of reducing androgen levels and expression of the androgen receptor protein relative to control rats (McKinnell et al., 2001, Rivas et al., 2002). This raises the important question of whether some of the genital tract abnormalities that arise from in utero administration of potent oestrogens are caused by lowered androgen levels and/or action.

\subsection{Anti-androgenic compounds in the environment}

There are a number of commonly used environmental chemicals that have been identified as having anti-androgenic properties. These chemicals have been administered to pregnant rodents during the period of reproductive tract development. When the male pups were examined, they displayed many of the abnormalities associated with flutamide administration. Some chemicals (vinclozolin, procymidone, linuron, p,p'DDE (1,1,1dichloro-2,2-bis(p-chlorophenyl)ethane) act as androgen receptor antagonists, others (phthalate esters) reduce androgen synthesis, but it is likely that other modes of action are also involved in the toxicity induced by these compounds (Gray et al.,2001). The following sections provide information on a few well-characterised examples of anti-androgenic 
compounds (i.e. vinclozolin, linuron, $\mathrm{p}, \mathrm{p}^{\prime} \mathrm{DDE}$ and phthalates etc.) and common environmental toxins reported to be involved in male reproductive toxicity.

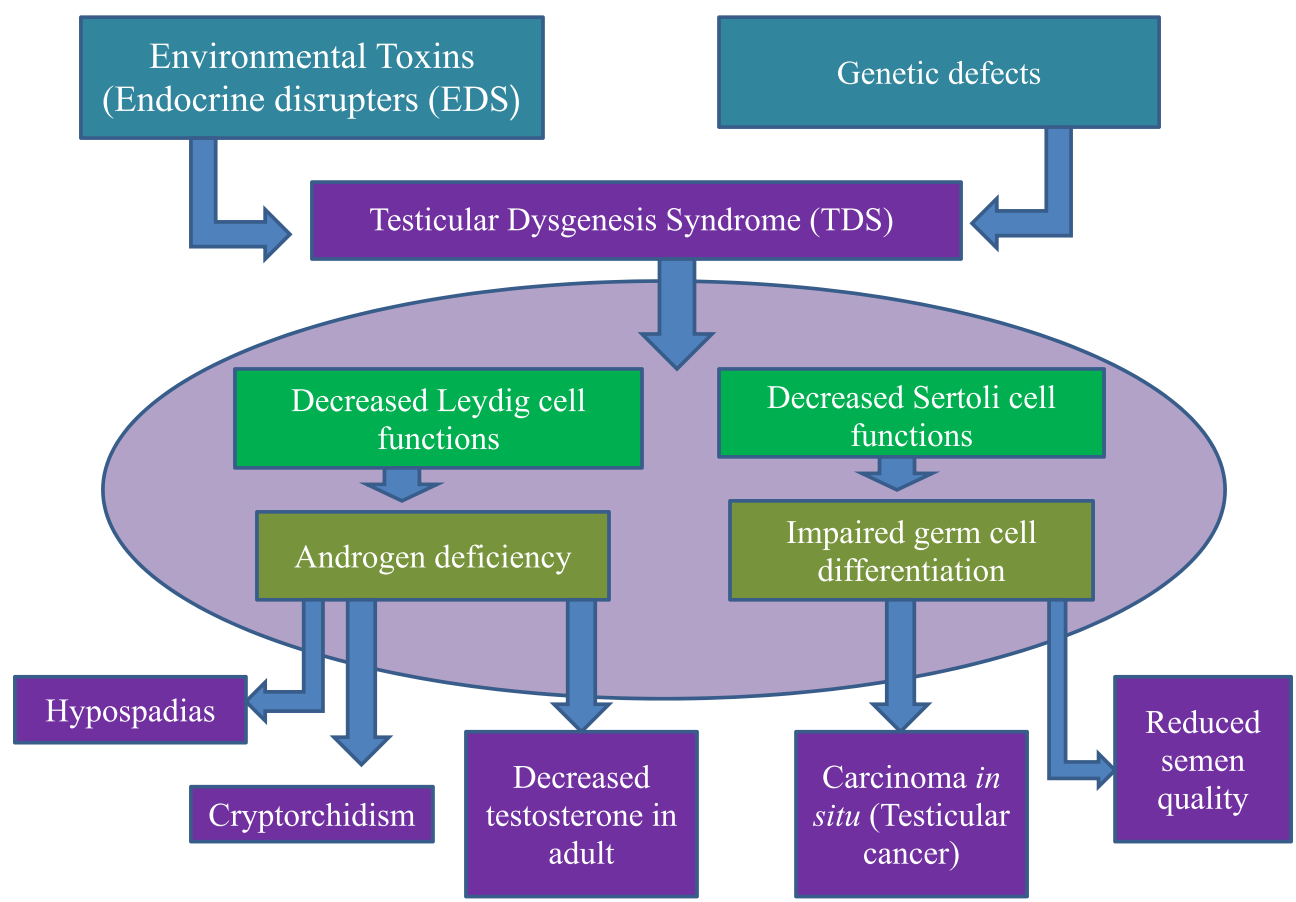

Fig. 3. Testicular dysgenesis syndrome. Both genetic and environmental factors affect testicular development and functions. Damage of the testicular cells (Leydig cells and Sertoli cells), disrupts androgen production from Leydig cells and secretion of paracrine factors from sertoli cells, leading to birth defects (hypospadias, cryptorchidism) and impaired germ cell differentiation, apparent later as reduced semen quality or in the worst cases as carcinoma in situ (CIS) of the testis and consequent testicular cancer. (Modified from Skakkeback et al. Human Reproduction, 2001).

\subsubsection{Polychlorinated Biphenyls (PCB)}

PCB make up a group of synthetic organic chemicals containing about 200 individual compounds. Some PCB bind to ERs and consequently PCB may exert their toxic effects through estrogenic activity (McKinney \& Waller, 1998). Alternatively, some PCB may produce reproductive toxicity through the production of free radicals. Rats exposed to mixtures of PCB demonstrated decreased superoxide dismutase and catalase activity in the testes following exposure (Peltola et al., 1994). PCB congeners have different mechanisms of action and therefore different effects on biological systems. Longitudinal studies of children with in utero or lactational exposure to PCB and other environmental chemicals are essential to assess the long-term effects of endocrine disruption. Prenatal and lactational exposure to PCB may exert adverse effects on male reproduction during subsequent adulthood. A wellstudied population exposed to PCB/PCDF-contaminated rice oil (Yu-Cheng exposure; 
Taiwan 1978-79) was followed to determine effects on male reproductive health. Median serum PCB levels measured in Yu-Cheng mothers was $26.8 \mathrm{ng} / \mathrm{ml}$ : a relatively high PCB exposure that would be expected to affect fetal development. Sexual development and semen quality were evaluated in Yu-Cheng sons, aged $16 \mathrm{yr}$ and older. Seminal volume and sperm concentration were not different between exposed and control boys. However, proportions of sperm with normal morphology and motility were reduced in exposed boys (Guo et al., 2000). The effects of PCB exposure on semen quality in men from the general population appear to affect differentiation of spermatids (spermiogenesis) and posttesticular development (sperm maturation), which would manifest as decreased sperm morphology and motility, respectively. Further studies of PCB exposure-both individual congeners and PCB mixtures - and sperm parameters are required.

\subsubsection{DDT and $p, p$ '-DDE}

The persistent pesticide, DDT, is broken down in the environment, and one of its metabolites is p, $\mathrm{p}^{\prime}-\mathrm{DDE}$, which has been shown to act as an androgen receptor antagonist both in vivo and in vitro (Kelce et al., 1995). Studies in which p, $\mathrm{p}^{\prime}$-DDE was administered to rats during development (gestational day (GD)14-18; $100 \mathrm{mg} / \mathrm{kg} /$ day) affected androgendependent aspects of male development such that it reduced anogenital distance, caused nipple retention and, depending on the rat strain, induced hypospadias (You et al., 1998). Another DDT derivative, methoxychlor and its metabolites, have been shown to interact with both oestrogen receptors and the androgen receptor (AR). The methoxychlor metabolite, 1,1-Trichloro-2,2-bis (4 hydroxyphenyl) ethane, is an oestrogen receptor (ER)- $a$ agonist, an ER- $\beta$ antagonist and an androgen receptor (AR) antagonist (Gray et al., 2001). This illustrates that these chemicals may act by more than one mechanism to induce effects on the exposed population. Moreover, several population studies conducted to examine the effects of DDT and metabolite exposure on male reproductive health support the hypothesis that DDT exposure is related to reduced semen quality. Significantly higher seminal concentrations of $p, p^{\prime}$-DDE were also reported in infertile patients compared to a fertile control group in India. Seminal fluid levels of fructose, $\gamma$-glutamyl transpeptidase, and acid phosphatase were positively correlated with $p, p^{\prime}$-DDE concentrations in infertile men. The high concentration of fructose, a marker for seminal vesicle function and an important energy source for sperm, may indicate non-utilization of fructose by sperm. DDT exposure may be associated with abnormal metabolism in sperm, including decreased fuel utilization, in infertile men (Pant et al., 2004). Mexican men living in the areas where DDT was used for malaria control, but without occupational exposure to DDT, exhibited serum levels of $p, p^{\prime}-$ DDE approximately 350-fold greater than Canadian men exposed to background environmental levels. $p, p^{\prime}$-DDE concentrations in the Mexican men were correlated with increases in SHBG concentration and negatively correlated with testosterone levels. Both semen volume and total sperm number were inversely correlated to $p, p^{\prime}$-DDE levels. Thus, androgen levels and semen quality are adversely affected by high $p, p^{\prime}$-DDE body burden (Ayotte et al., 2001). The studies examining DDT exposure and semen quality report consistent effects on sperm motility and sperm morphology, similar to the PCB studies. The increased SHBG concentrations associated with serum $p, p^{\prime}$-DDE described by Ayotte et al.,(2001) provides a possible mechanism for observed reductions in plasma testosterone and sperm number. By inducing SHBG synthesis, $p, p^{\prime}$-DDE may exert its antiandrogenic effects by reducing the amount of bioavailable testosterone, thereby impairing spermatogenesis. 
Further, more extensive correlation studies on the serum levels of DDT and metabolites in mothers of infertile men are required. These studies would provide insight into the effects of in utero exposure to DDT on semen quality of adult males.

\subsubsection{Dioxins}

Tetrachlodibenzo- $p$-dioxin (TCDD) is a carcinogen, demonstrated to target the endocrine system in experimental animals. Humans are exposed to dioxins through pulp and paper industry emissions, use of contaminated herbicides (now reduced in industrialized countries), and waste incineration emissions. Dioxins are lipophilic, slowly metabolized, and thus are not easily eliminated leading to bioaccumulation. Secondary dioxin exposures include dietary uptake via contaminated breast milk, meat, fish, and other dairy. Dioxins along with polycyclic aromatic hydrocarbons (PAH) and polyhalogenated biphenyls bind to the aryl hydrocarbon receptor (AhR). AhR ligands induce cell proliferation, differentiation, and apoptosis, although the mechanisms of these stimulations are not fully understood. It is known that human sperm possess AhR and may therefore be directly susceptible to dioxin (Khorram et al., 2004). A range of endocrine effects are reported in experimental animals following dioxin exposure. These include disruption of the HPT axis feedback mechanisms leading to alterations in serum levels of testosterone, dihydrotestosterone (DHT), E2, and $\mathrm{LH}$, as well as modifications of the metabolism processes/events of estrogens and androgens (Birnbaum \& Tuomisto, 2000). There are few published studies reporting human exposure to dioxins. Agent Orange, which contains TCDD as its contaminant, was used during the Vietnam War and exposure was documented in veterans of Operation Ranch Hand (the unit responsible for aerial herbicide spraying in Vietnam from 1962 to 1971; (Stone, 2007). Detectable TCDD levels in serum and seminal plasma were evident in U.S. veterans two to three decades following their Vietnam military service. Reproductive parameters including serum testosterone, FSH, LH, and testicular abnormalities were not associated with serum TCDD levels in the exposed men. It may be possible that the effects of dioxin on reproductive parameters were no longer evident at the time of the study, several decades after the use of Agent Orange. As semen quality can only be evaluated by follow-up study, the acute effects of exposure to Agent Orange on male reproductive health are unknown. Another study of 101 men from the general population in Belgium assessed TCDD exposure and semen quality. TCDD exposure was measured as dioxin-like activity in serum. Increases in serum dioxin-like activity were associated with decreased seminal volume resulting in elevated sperm concentrations. Total testosterone levels were significantly reduced in men with high serum dioxin-like activity. However, there was no significant association with LH, inhibin B, FSH, total sperm numbers, or sperm morphology (Dhooge et al., 2006). There are few epidemiological studies evaluating reproductive outcomes and particularly semen quality following TCDD and dioxin exposure. However, it is more relevant to consider the effects of dioxin at environmental concentrations on male reproductive health. A possible mechanism for infertility may be mediated by dioxin interacting with $\mathrm{AhR}$ on human sperm with implications for capacitation, acrosome reaction, sperm-egg binding, and fertilization. More studies are required to examine the effects of dioxin on semen quality.

\subsubsection{Phthalates esters}

Phthalate esters are abundant industrial chemicals used in the production of plastics and are present in many personal care products including cosmetics. Phthalates are a family of 
compounds and only a few induce male reproductive tract abnormalities. Gray et al., (2000) compared the ability of six phthalate esters (diethylhexyl phthalate, DEHP; benzylbutyl phthalate, BBP; diisononyl phthalate, DINP; dimethyl phthalate, DMP; diethyl phthalate, DEP; dioctyl terephthalate, DOTP; all administered at $750 \mathrm{mg} / \mathrm{kg}$ body weight from GD14 to postnatal day (PND) 3) to induce malformations of the reproductive tract. This study assessed changes in many androgenic endpoints and found that only DEHP, BBP and to a lesser degree DINP induced alterations in all aspects of androgen-regulated male reproductive endpoints. Exposure to diethyl hexyl and dibutyl phthalates is associated with adverse effects on sperm motility (Fredricsson et al., 1993). Animal studies consistently demonstrated that phthalate esters are male reproductive toxicants (Park et al., 2002), with exposure associated with testicular atrophy, spermatogenetic cell loss, and damage to the Sertoli cell population. Phthalate monoesters target Sertoli cell functions in supporting the spermatogenesis process. This may be due to the effect of phthalates in reducing the ability of Sertoli cells to respond to FSH (Hauser et al., 2005). Initial reports on the effects of phthalates on male reproductive tract development focussed on the gross changes such as reduced anogenital distance, hypospadias, malformed epididymis and, in later studies, nipple retention (Mylchreest et al., 2000). Only a few studies give a more detailed account of the histological changes observed in the testis after in utero phthalate exposure and demonstrate that the fetal testis is directly affected by phthalates during fetal and neonatal testis differentiation (Parks et al., 2000; Fisher et al., 2003). Some of these alterations are permanent and affect the function of the testis in adult life and are similar to the histological changes which are now being shown in patients with testicur dysgenesis syndrome (TDS; Skakkebaek et al., 2003). The production of testosterone is critical for the normal masculinization of the male reproductive tract, as already discussed. It has been shown that DBP and DEHP are both capable of inhibiting the production of testosterone by the fetal testis (Parks et al., 2000; Fisher et al., 2003). Testosterone synthesis by the fetal testis is first detectable by GD15, reaches a peak at around GD18/19, and remains high until birth. However, phthalate treatment induces a $60-85 \%$ reduction in testosterone synthesis during this critical developmental window, reducing testosterone levels to a similar level to those found in females (Parks et al., 2000). This reduction in testosterone is a factor in the occurrence of hypospadias and cryptorchidism observed after phthalate treatment. This is not to suggest that phthalate exposure causes TDS in humans, merely that the administration of very high doses of DBP to pregnant rats induces a TDS-like syndrome in the male offspring that shows many analogous features to human TDS. It is plausible, given how highly conserved the pathways of fetal development are, that phthalate administration may disrupt some common mechanistic pathways which if altered in humans could be helpful in determining the pathogenesis of human TDS. In both the human syndrome and the rodent model, abnormal testicular development or dysgenesis is evident by the abnormal organisation of these tissues. In humans, histological evidence of testicular dysgenesis (immature seminiferous tubules with undifferentiated Sertoli cells, microcalcifications and Sertoli cell only (SCO) tubules, Leydig cell hyperplasia, morphologically distorted tubules and the presence of carcinoma in situ (CIS) cells) have been found in biopsies of the contralateral testes of testicular germ cell cancer patients and in biopsies from patients with infertility, hypospadias and cryptorchidism (Skakkebaek et al., 2003). These studies support the hypothesis that all of these disorders (low sperm counts, 
cryptorchidism, hypospadias and testicular cancer) are associated with TDS. The in utero administration of DBP to rodents during the sensitive period of tissue morphogenesis permanently alters the testis and produces foci of testicular dysgenesis (immature seminiferous tubules with undifferentiated Sertoli cells, SCO tubules, Leydig cell hyperplasia, morphologically distorted tubules and the presence of abnormal germ cells) which persist in the adult animal (Fisher et al., 2003). The downstream consequences of altered Sertoli cell (and subsequently Leydig cell) function may be a key cause of many of the observed changes in both human TDS and the rat TDS-like model due to the central role of this cell type in driving testis morphogenesis in both rodents and humans. Several population studies evaluated phthalate ester exposure and semen quality. A randomized controlled study of men with unexplained infertility reported a negative correlation between seminal plasma phthalate ester concentration and sperm morphology (Rozati et al., 2002). Environmental phthalate levels measured by urinary metabolite, were reported to be associated with increased DNA damage in sperm (Duty et al., 2003). The studies measuring phthalate levels and semen quality seem to suggest an effect on sperm morphology and motility, rather than on total sperm numbers. Hauser et al.,(2005) suggest a mechanism by which PCB exposure may extend the bioavailability of phthalate metabolites, which in turn adversely affect semen quality. As human exposure consists of phthalate mixtures, along with xenobiotics, studies designed to test or measure single phthalate esters fail to appropriately characterize risks associated with these chemicals.

\subsubsection{Phytoestrogens}

Phytoestrogens are nonsteroidal plant-derived compounds with potent estrogenic activity. There are four main groups of phytoestrogens: isoflavonoids, flavonoids, coumestans, and lignans. Phytoestrogens exert their action via multiple mechanisms. Phytoestrogens interact with both ERa and ER $\beta$, thereby inducing weak estrogenic and antiestrogenic actions (Kuiper et al., 1998). Coumestrol and genistein, two phytoestrogens, exhibit a higher affinity for ERß than for ERa (Whitten \& Naftolin, 1998). Some phytoestrogens exert an inhibitory action on steroidogenic enzymes (Strauss et al., 1998). For example, isoflavonoids and lignans inhibit 5a-reductase activity, thereby reducing the conversion of testosterone to the active form DHT. A number of phytoestrogens, including lignans, isoflavonoids daidzein and equol, enterolactone, and genistein, were found to induce SHBG production in the liver (Adlercreutz et al., 1987). There are few studies measuring the effects of phytoestrogens on semen parameters in men. The effects of short-term phytoestrogen supplementation on semen quality and endocrine function were examined in a group of young, healthy males. Subjects received $500 \mathrm{mg}$ supplements containing $40 \mathrm{mg}$ of phytoestrogens isoflavones genistein, daidzein, and glycitein daily for 2 months and donated semen and blood for 2 months before and 4 months after supplementation (Mitchell et al., 2001). Testicular volume was not influenced by phytoestrogen supplementation; nor did serum E2, testosterone, FSH, or LH differ between the supplement-taking group and the control group who did not take supplements. Finally, phytoestrogen supplementation did not produce changes in seminal volume, sperm concentration, sperm count, and sperm motility (Mitchell et al., 2001). A case report described therapeutic phytoestrogen supplementation $(80 \mathrm{mg} /$ day for 6 months $)$ to an oligospermic man, which did sufficiently improve semen parameters such that intrauterine insemination was performed and the couple was able to conceive (Casini et al., 2006). To date, evidence linking dietary consumption of phytoestrogens and reduced semen quality is insufficient and requires further study. 


\subsubsection{Pesticides, fungicides and herbicides}

The U.S Environmental Protection Agency (EPA) defines a pesticide as "any substance or mixture of substances intended for preventing, destroying, repelling, or lessening the damage of any pest," which may include plants, weeds, animals, insects, and fungus. Many epidemiological studies use the generic term pesticides to refer to a broad range of structurally unrelated compounds with different mechanisms of action, biological targets, and target pests. Epidemiological studies that evaluate the effects of these chemicals on male reproductive parameters often lack direct, quantitative measures of exposure. A study of participants from The Study for Future Families evaluated semen quality and pesticide exposures in male partners of pregnant women attending prenatal clinics in Missouri and Minnesota (Swan et al., 2003) Urinary levels of metabolites from the pesticides alachlor, diazinon, atrazine, and metolochlor were detected more often in men from Missouri, representative of the pesticides used in the agricultural practices of this state. Pesticide metabolites of chlorpyrifos/chlorpyrifos methyl (3,5,6-trichloropyridinol) and methyl parathion (4-nitrophenol) were detected more frequently in men from Minnesota. For the Missouri group, there was an association between low semen quality and urinary levels of chlorpyrifos and parathion metabolites. Further, increased levels of herbicides alachlor and metoachlor were associated with decreased sperm morphology and concentration. In contrast, there was no association between levels of any of these pesticides and their metabolites and semen parameters within the Minnesota group (Swan et al., 2003). A followup study focused on the men from Missouri, using a nested case-control design (cases: men with low semen parameters; controls: men with normal parameters). Urinary levels of metabolites of eight currently used pesticides were measured and correlated with semen quality. Men with elevated metabolite levels of alachlor and atrazine (herbicides) and diazinon (2-isopropoxy-4-methyl-pyrimidinol insecticide) were significantly more likely to have poor semen quality than controls (Swan, 2006). This study provide evidence that environmental exposures differ between regions, even within the same country. Different agricultural practices will create regional variation in the amounts and types of pesticides used, leading to differences in biological effects. A study in male infertility patients in Massachusetts measured urinary metabolites of carbaryl/naphthalene and chlorpyrifos. Sperm concentration, motility, and, to a lesser extent, morphology were reduced in men with elevated exposure to carbaryl/naphthalene (as measured by urinary levels of the metabolite 1-naphthol) and to chlorpyrifos (as measured by urinary levels of the metabolite 3,5,6-trichloro-2-pyridinol [TCPY]) (Meeker et al., 2004). The mechanism of action of carbaryl may be related to the production of reactive oxygen species (ROS) rather than endocrine disruption. Carbaryl produced lipid peroxidation at low concentrations, which in turn induced the sperm plasma membrane to lose its fluidity and integrity, thereby impairing sperm motility (Meeker et al., 2004). Generally, the studies reviewed here demonstrated a relationship between pesticide exposure and reduced semen quality. However, toxicology studies using animal models are essential to understand the biological mechanisms underlying the adverse reproductive affects caused by pesticide exposure in the male.

\subsubsection{Vinclozolin}

Vinclozolin is a dicarboximide fungicide that has two active metabolites, M1 and M2, which have anti-androgenic properties. In vivo and in vitro experiments demonstrate that these compounds act as potent androgen receptor antagonists, and administration to pregnant 
rats results in abnormalities of androgen-regulated sexual differentiation similar to those induced by flutamide, e.g. reduced anogenital distance, nipple retention, hypospadias, undescended testes and small or absent accessory glands (Gray et al., 2001). Studies have tried to define the 'sensitive window' for exposure to vinclozolin, and have determined that administration to pregnant rats during gestational day (GD) 14-19 induced reproductive tract malformations, with treatment over GD16-17 causing the most severe malformations (Wolf et al., 2000). This illustrates that the whole period of male reproductive tract differentiation is sensitive to the effects of anti-androgens.

\subsubsection{Linuron}

Linuron is a urea-based herbicide which acts as a weak androgen receptor antagonist in vitro and in vivo, and disrupts androgen-dependent male reproductive tract development after gestational exposure (Gray et al., 2001). When administered to pregnant rats (GD 14$18 ; 100 \mathrm{mg} / \mathrm{kg} /$ day) the male pups displayed a reduced anogenital distance and retention of areolas (Gray et al., 1999). Linuron failed to induce either hypospadias or undescended testes, suggesting that linuron affects testosterone-but not DHT-mediated development, though how this occurs is not known (McIntyre et al., 2002).

\subsubsection{Tobacco smoke}

It is beyond the scope of this review to provide a detailed review of the literature on cigarette smoking and semen quality. However, PAH (polycyclic aromatic hydrocarbons), the major carcinogenic components of cigarette smoke (Vine, 1996), were found to activate aryl hydrocarbon receptor (AhR), suggesting that tobacco smoke may represent a chemical mixture with endocrine disrupting activity. There is extensive evidence demonstrating that exposure to tobacco smoke is associated with reduced semen quality (Vine, 1996). An inverse dose-dependent relationship between smoking and semen volume, total sperm count, and percent motile sperm was reported following a large cross-sectional study of 2542 healthy Danish men. Sperm concentration was 19\% lower in heavy smokers compared to non-smokers. Serum LH and testosterone were positively correlated with smoking (Ramlau-Hansen et al., 2007). The incidence of bilateral cryptorchidism in a sample of cryptorchid Danish boys was increased in children of smoking mothers. Testicular biopsies from boys exposed in utero/neonatal to tobacco smoke demonstrated a decreased number of spermatogonia and gonocytes per tubule cross section (Thorup et al., 2006). Similarly, a large cross-sectional European study of 889 Danish men, 221 men from Norway, 313 Lithuanian men, and 190 men from Estonia reported reductions of sperm concentrations by $20 \%$ in sons exposed to prenatal tobacco smoke (Jensen et al., 2004), while a separate study described an inverse dose-dependent association between sperm concentration and prenatal tobacco exposure, measured in adult sons of 522 Danish women (Jensen et al., 2005). The association between impaired semen quality and smoking is fairly well established (Vine, 1996). Although epidemiological studies of male reproductive function were designed to avoid the confounding effects of smoking, by limiting samples to non-smokers or segmenting samples according to smoking status, the interaction effects of tobacco smoke, alcohol, and other lifestyle factors are often not considered. An important study by Robbins et al.,(1997) did investigate the interactions of caffeine, alcohol, and cigarette smoking on sperm aneuploidy, determining that incidence of sperm abnormalities decreased after controlling for age and other lifestyle factors. 


\subsubsection{Medications and male reproductive toxicity}

There are a variety of prescription medications that can lead to male infertility, often temporary but sometimes permanent. Arthritis medication, depression drugs, high blood pressure medication, drugs for digestive problems as well as antibiotics and cancer drugs are just a few of the medications that can lead to interferences with sperm production, sexual function and ejaculation (Nudell et al., 2002). Here is a look at some of the common medications and drugs that can cause a man to experience fertility problems.

\subsubsection{Antihypertensive}

Although most men who are treated for hypertension are older, the recent focus on the importance of blood pressure control has led to greater numbers of younger patients on antihypertensives. Many of these medications are commonly associated with erectile dysfunction but most do not directly affect fertility. One exception is spironolactone, which acts as an anti-androgen and has been associated with impaired semen quality. Calcium channel blockers (e.g. nifedipine) have been reported to cause reversible functional defects in sperm, impairing their ability to fertilize eggs without affecting sperm production or standard semen analysis parameters; however, not all investigators report these types of effects. Diuretics can affect function by decreasing penile blood flow, and beta-blockers may affect libido and erectile function (Benoff et al., 1994).

\subsubsection{Hormones}

Diethylstilbestrol (DES) was given to pregnant women in the 1950s, and reports of epididymal cysts and cryptorchidism (undescended testes) in males with prenatal DES exposure have raised concerns about fertility; however, follow-up studies on adult men with prenatal DES exposure have revealed no adverse effects on fertility (Wilcox et al., 1995). Exogenous androgens are well known to induce hypogonadotropic hypogonadism. This may be induced directly by testosterone supplementation or by use of synthetic anabolic steroids, leading to azoospermia. This hypogonadism is usually reversible but may take 3 to 6 months, and some patients do not recover pituitary function. It is important to remember that testosterone replacement therapy in younger men may lead to infertility. Dehydroepiandrosterone (DHEA) is a natural steroid prohormone precursor of androsterone, testosterone, and estrogen. DHEA is commonly taken and easily available over the counter. Antiandrogens and estrogens can adversely affect fertility by altering the HPG axis or decreasing libido or erectile function, while progesterones act by decreasing libido or erectile function (Nudell et al., 2002).

\subsubsection{Antiandrogens}

Finasteride and dutasteride are antiandrogens that act by inhibiting 5-alpha-reductase. Finasteride has also been used to treat male-pattern baldness. These drugs increase the risk of low ejaculate volumes and libido, as well as cause erectile and ejaculatory dysfunction; however, men taking low doses of finasteride for hair loss have shown no changes in semen parameters (Overstreet et al., 1999).

\subsubsection{Antibiotics}

Many antibiotics have been reported to exert adverse effects on male fertility; however, there are few human data on the majority of these medications. High doses of nitrofurantoin have been reported to cause early maturation arrest at the primary spermatocyte stage but 
the more common short-term low-dose therapy is not likely detrimental. While in vitro data on erythromycin, tetracycline, and gentamycin suggest the potential for adverse effects on fertility, documentation of an in vivo effect in humans is lacking (Hargreaves et al., 1998). Sulfasalazine, used in the treatment of ulcerative colitis, is well known to cause defects in human sperm concentration and motility. Aminoglycosides, type of antibiotics is generally used for serious bacterial infections, like $\mathrm{TB}$, and are administered under medical supervision. Aminoglycosides can negatively impact sperm production while neomycin has been shown to reduce both sperm count and motility. Macrolides, in addition to being used to treat chlamydia and Legionnaires disease, macrolides are similar to penicillin and can be used in place of it in people with a penicillin allergy. Macrolides research has mainly focused on animals, where it has been found that the antibiotic can decrease sperm motility as well as kill off sperm. It is believed that the antibiotic produces similar results in humans (Schlegel et al., 1991).

\subsubsection{Psychotherapeutic agents}

Many psychotherapeutic agents affect male fertility by suppressing the HPG axis and decreasing erectile function and libido. Indeed, one of the most significant side effects of the antidepressants is elevation of serum prolactin, leading to significant but reversible suppression of spermatogenesis (Nudell et al., 2002). Psychotherapeutic agents include antipsychotics, tricyclic and selective serotonin reuptake inhibitor (SSRI) or selective norepinephrine reuptake inhibitor (SNRI) antidepressants, monoamine oxidase inhibitors (MAOIs), phenothiazines, and lithium. There are now large numbers of patients taking SSRI or SNRI medications, many of which have significant fertility effects.

\subsubsection{Anticancer drugs}

Doxorubicin hydrochloride, Goserelin acetate, methotrexate, or fluorouracil all are the drugs used to treat various types of cancer. However, these drugs have significant side effects on sexual behaviour, altered fertility and sperm count (Nudell et al., 2002).

\subsection{Chemotherapeutic agents}

Chemotherapy for the treatment of cancer can have devastating effects on male fertility through the impairment of spermatogenesis; indeed, alkylating agents, antimetabolites, and the vinca alkaloids are all gonadotoxins. The alkylating agent, cyclophosphamide alters male fertility; treatment with $1-2 \mathrm{mg} / \mathrm{kg}$ for more than 4 months increases the incidence of azospermia and oligospermia in adult male patients (Qureshi et al., 1972). In patients with testicular cancer, the cumulative dose of cisplatin determines whether spermatogenesis is impaired irreversibly. Most patients will become azoospermic, with the majority recovering spermatogenesis within 4 years. The majority of Hodgkin's disease or leukemia patients become azoospermic after chemotherapy; this may or may not lead to permanent sterility. After treatment with mitoxantrone, vincristine, vinblastine, and prednisone combination therapy plus abdominal radiotherapy for Hodgkin's disease, sperm counts and motility were restored to pre-treatment levels in most patients (Magelseen et al., 2006).

\subsubsection{Miscellaneous medications}

Cimetidine has been reported to have antiandrogenic effects that induce gynecomastia and decreases in sperm count. Immune modulators are commonly used but, unfortunately, clear human data regarding male fertility for interferon or the immunosuppressant mycophenolate mofetil are lacking. Although cyclosporine has been found to induce 
impaired fertility in rats, there are no human data available (Nudell et al., 2002). Epilepsy has been associated with decreased testosterone levels and increased estrogen levels leading to reductions in libido and to erectile dysfunction. Medications used to treat epilepsy (eg, valproate, oxcarbazepine, and carbamazepine) may worsen hormonal abnormalities and have been associated with some sperm morphologic defects (Isojarvi et al., 2004).

\subsubsection{Recreational and illicit substances and male reproductive toxicity}

Heavy marijuana use has been associated with gynecomastia, decreased serum testosterone levels, decreased sperm concentration, and pyospermia (white cells in the semen indicating possible infection) (Close et al., 1990). Patients experience variable sensitivity to marijuana, and it may take 2 to 3 months for symptoms to improve.

Oligospermia (abnormally low sperm concentration in the ejaculate) and defects in sperm morphology and motility have been reported in users of cocaine. Opiates have also been shown to decrease libido and erectile function through induction of hypogonadotropic hypogonadism. This also is important to note when prescribing opioids for pain. Chronic opioid use whether, oral or intrathecal, may lead to sexual dysfunction (Bracken et al., 1990). Cumulative evidence suggests that cigarette smoking may have a deleterious effect on male fertility by reducing sperm production, motility, and morphology. Cigarette smoking may also lead to development of pyospermia, decreased sperm penetration, and hormonal alterations (Nudell et al., 2002; Close et al., 1990). Long-term abuse of alcohol has detrimental effects in the HPG axis. Alcoholics exhibit significant decreases in semen volume, sperm count, motility, and number of morphologically normal sperm. They also show signs of pyospermia. Alcohol in excess can thus exert profound deleterious effects on all aspects of the male reproductive system. However, there is no evidence that moderate alcohol intake impairs male fertility (Nudell et al., 2002; Close et al., 1990).

The examples of few chemicals which are reported to disrupt the sex hormones and/or damage the male in animal studies are summarized below (Woodruff et al., 2008).

\begin{tabular}{|c|c|}
\hline $\begin{array}{l}\text { Common environmental } \\
\text { Toxicants }\end{array}$ & Common uses and routes of exposure \\
\hline
\end{tabular}

Heavy Metals
(Mainly cadmium, Lead

Population exposed to cadmium and lead via contaminations found in and arsenic) drinking water and food, while occupational exposure takes place during mining or manufacturing of batteries and pigments or industrial a. Testicular toxicity b. Low sperm count and motility and density. c. Reduce male fertility d. Foetal toxicity and activities such as smelting and refining organs. metals and municipal waste incineration.

Volatile organic compounds Mostly occupational exposure in (Toluene, benzene and industrial workers. xylene)

Phthalates Phthalates are a group of chemicals $\mathrm{DBP}=\operatorname{di}(\mathrm{n})$ butylphthalate used to impart flexibility to plastic $\mathrm{DiBP}=\mathrm{di}$ (iso)butylphthalate polyvinyl chloride (PVC) products as a. Testicular toxicity

b. Low sperm count and motility and density. c. Reduce male fertility

a. Testicular toxicity

b. Reduce anogenital distance, hypospadias and 


\begin{tabular}{|c|c|c|}
\hline $\begin{array}{l}\text { Common environmental } \\
\text { Toxicants }\end{array}$ & Common uses and routes of exposure & $\begin{array}{l}\text { The effects on male } \\
\text { reproductive system }\end{array}$ \\
\hline $\begin{array}{l}\text { BBP = benzyl butyl } \\
\text { phthalate } \\
\text { DEHP = di }(2- \\
\text { ethylhexyl)phthalate } \\
\text { DPP = dipentyl phthalate } \\
\text { DINP = diisononyl } \\
\text { phthalate } \\
\text { DCHP = dicyclohexyl } \\
\text { phthalate }\end{array}$ & $\begin{array}{l}\text { well as in other applications, including } \\
\text { pharmaceuticals, and pesticides. There } \\
\text { is widespread human exposure with } \\
\text { reported uses in building materials, } \\
\text { household furnishings, clothing, } \\
\text { cosmetics, dentures, medical tubing and } \\
\text { bags, toys, modelling clay, cars, } \\
\text { lubricants, waxes and cleaning } \\
\text { materials. Exposure may arise via the } \\
\text { air, through absorption when used on } \\
\text { the skin, and through the diet. }\end{array}$ & $\begin{array}{l}\text { undescended of testes in } \\
\text { immature male. } \\
\text { c. Reduce male fertility } \\
\text { d. Foetal toxicity and } \\
\text { malformation of male } \\
\text { organs. }\end{array}$ \\
\hline Paraben & $\begin{array}{l}\text { Paraben is the name given to a group } \\
\text { of chemicals used as preservatives in } \\
\text { cosmetics and body care products, } \\
\text { including deodorants, creams and } \\
\text { lotions. They are able to penetrate the } \\
\text { skin }\end{array}$ & $\begin{array}{l}\text { a. Hormone mimicking } \\
\text { activities } \\
\text { b. Reduce synthesis of } \\
\text { testosterone }\end{array}$ \\
\hline Triclosan & $\begin{array}{l}\text { Triclosan is an anti-bacterial and anti- } \\
\text { fungal chemical widely used in } \\
\text { personal care products such as some } \\
\text { soaps, toothpaste etc. Triclosan has } \\
\text { also been added to plastic products } \\
\text { such as kitchen chopping boards. }\end{array}$ & $\begin{array}{l}\text { a. Hormone mimicking } \\
\text { activities } \\
\text { b. Reduce synthesis of } \\
\text { testosterone }\end{array}$ \\
\hline Triclocarban & $\begin{array}{l}\text { Triclocarban (TCC or } 3,4,4^{\prime}- \\
\text { trichlorocarbanilide) is also used as an } \\
\text { anti- bacterial in personal care } \\
\text { products such as soaps. }\end{array}$ & $\begin{array}{l}\text { a. It has sex hormone } \\
\text { disrupting properties. }\end{array}$ \\
\hline $\begin{array}{l}\text { BPA } \\
\text { (Bisphenol A) }\end{array}$ & $\begin{array}{l}\text { BPA is the building block of } \\
\text { polycarbonate plastic used in baby } \\
\text { bottles, CDs, motor cycle windshields } \\
\text { etc. It is also used for the production of } \\
\text { epoxy resins used in the coating of the } \\
\text { food packaging. }\end{array}$ & $\begin{array}{l}\text { a. Oestrogenic activities } \\
\text { b. Altered male } \\
\text { reproductive organs and } \\
\text { induce early puberty } \\
\text { c. Anti androgenic activity. }\end{array}$ \\
\hline $\begin{array}{l}\text { Penta-BDE } \\
\text { (Penta-brominated } \\
\text { diphenyl ether) }\end{array}$ & $\begin{array}{l}\text { There are actually } 3 \text { commercial PBDE } \\
\text { products, which predominantly } \\
\text { contain deca, octa and penta-BDEs, } \\
\text { and are therefore called by these } \\
\text { names. PBDEs are used as flame } \\
\text { retardants to prevent fire taking hold } \\
\text { quickly. Penta-BDE is used in } \\
\text { polyurethane foam, for example, in } \\
\text { mattresses and car and aeroplane } \\
\text { seats. Apart from exposure via dust it } \\
\text { is possible to transfer from hand to } \\
\text { mouth. }\end{array}$ & $\begin{array}{l}\text { a. Altered male } \\
\text { reproductive organs } \\
\text { c. Anti androgenic } \\
\text { properties. }\end{array}$ \\
\hline
\end{tabular}


Common environmental Common uses and routes of exposure The effects on male Toxicants reproductive system

\begin{tabular}{|c|c|c|}
\hline PCBs & $\begin{array}{l}\text { PCBs are used in a variety of } \\
\text { applications, including electrical } \\
\text { applications, dielectric fluids for } \\
\text { transformers and capacitors, hydraulic } \\
\text { and heat transfer systems, lubricants, } \\
\text { gasket sealers, paints, fluorescent } \\
\text { lights, plasticizers, adhesives, } \\
\text { carbonless copying paper, flame } \\
\text { retardants, and brake linings. Human } \\
\text { exposure also arises due to } \\
\text { contamination of the food chain. }\end{array}$ & $\begin{array}{l}\text { a. Hormone mimicking } \\
\text { activities } \\
\text { b. Anti androgenic } \\
\text { properties. }\end{array}$ \\
\hline Dioxins & $\begin{array}{l}\text { Dioxins are a group of chemicals } \\
\text { which are not intentionally produced, } \\
\text { but are emitted during incomplete or } \\
\text { relatively low temperature } \\
\text { combustion. They can come from } \\
\text { industrial or domestic sources, } \\
\text { wherever a chlorine source is present. } \\
\text { Such sources include, for example, } \\
\text { domestic bonfires with PVC plastic, } \\
\text { incinerators, certain chemical and } \\
\text { metal factories (particularly } \\
\text { aluminium recovery sites), paper pulp } \\
\text { production using chlorine, and coal } \\
\text { burning in power stations and in fire- } \\
\text { places in the home. Exposure can arise } \\
\text { from inhalation, but mainly comes } \\
\text { from contamination of food. }\end{array}$ & $\begin{array}{l}\text { a. Sex hormone disruptor } \\
\text { b. Testicular dysfunctions } \\
\text { c. Low sperm count } \\
\text { d. Sperm abnormalities }\end{array}$ \\
\hline Diesel fuel Exhaust & $\begin{array}{l}\text { As diesel is used as a fuel in many cars } \\
\text { and lorries, diesel exhaust is } \\
\text { widespread. }\end{array}$ & $\begin{array}{l}\text { a. Disrupts androgen action } \\
\text { b. Prenatal exposure in } \\
\text { animals leads to endocrine } \\
\text { disruption after birth and } \\
\text { suppresses testicular } \\
\text { function in male rats. }\end{array}$ \\
\hline $\begin{array}{l}\text { Tobacco smoke } \\
\text { (Polycyclic aromatic } \\
\text { hydrocarbons (PAH) }\end{array}$ & It includes active or passive smoking & $\begin{array}{l}\text { a. Blocks androgen } \\
\text { synthesis } \\
\text { b. Testicular dysfunctions } \\
\text { c. Low sperm count } \\
\text { d. Sperm abnormalities }\end{array}$ \\
\hline $\begin{array}{l}\text { Alkylphenols } \\
\text { Nonylphenol } \\
\text { Octylphenol }\end{array}$ & $\begin{array}{l}\text { Nonylphenol is the breakdown } \\
\text { product of the surface active agent, } \\
\text { nonylphenol ethoxylate. Many uses } \\
\text { including in domestic cleaning and } \\
\text { industrial and institutional cleaning, } \\
\text { and in textiles and leather processing. } \\
\text { Octyl phenol is used in the production }\end{array}$ & $\begin{array}{l}\text { a. Hormone mimicking } \\
\text { activities } \\
\text { b. Reduce synthesis of } \\
\text { testosterone } \\
\text { c. Reduce testicular size } \\
\text { d. reduce male fertility and } \\
\text { sperm number and quality. }\end{array}$ \\
\hline
\end{tabular}




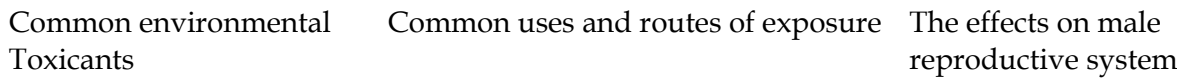

\begin{tabular}{|c|c|c|}
\hline & $\begin{array}{l}\text { of phenol/ formaldehyde resins } \\
\text { (Bakelite) and in the production of } \\
\text { octylphenol ethoxylates, and used in } \\
\text { the formulation of printing inks and in } \\
\text { tyre manufacture }\end{array}$ & \\
\hline $\begin{array}{l}\text { DDT } \\
\text { (break-down product DDE). }\end{array}$ & $\begin{array}{l}\text { DDT is an insecticide which was used } \\
\text { extensively on crops, but is now only } \\
\text { used in a few countries against the } \\
\text { malaria-bearing mosquito. DDT and } \\
\text { DDE last in the soil for a very long } \\
\text { time, potentially for hundreds of years. } \\
\text { Unfortunately, due to this persistence, } \\
\text { it is still found in some produce, such } \\
\text { as vegetables, fish and liver. DDE is } \\
\text { also found as a persistent contaminant } \\
\text { in our bodies. The DDT breakdown } \\
\text { product or metabolite, p, p'-DDE, is } \\
\text { able to block testosterone. }\end{array}$ & $\begin{array}{l}\text { a. Hormone mimicking } \\
\text { activities } \\
\text { b. Reduce synthesis of } \\
\text { testosterone }\end{array}$ \\
\hline $\begin{array}{l}\text { Linuron } \\
\text { Diuron }\end{array}$ & $\begin{array}{l}\text { Linuron and diuron are herbicide used } \\
\text { to control weeds on hard surfaces such } \\
\text { as roads, railway tracks and in crops } \\
\text { and forestry. It has been detected in } \\
\text { tap water and as a residue in } \\
\text { vagetables such as carrots, parsnips } \\
\text { and spinach. }\end{array}$ & $\begin{array}{l}\text { a. Anti-androgenic } \\
\text { properties }\end{array}$ \\
\hline $\begin{array}{l}\text { Vinclozolin } \\
\text { Procymidone } \\
\text { Iprodione } \\
\text { Prochloroz } \\
\text { Fenarimol }\end{array}$ & $\begin{array}{l}\text { These are all fungicide used on fruits } \\
\text { and vegetables. }\end{array}$ & $\begin{array}{l}\text { a. Blocks testosterone action } \\
\text { b. Reduce testosterone } \\
\text { synthesis } \\
\text { c. Anti-androgenic } \\
\text { properties } \\
\text { d. Feminize male offspring. }\end{array}$ \\
\hline $\begin{array}{l}\text { Fenarimol } \\
\text { Fenitrothion } \\
\text { Chlorpyrifos-methyl }\end{array}$ & $\begin{array}{l}\text { These are all insecticides are used, for } \\
\text { example, on apples, plums, barries, } \\
\text { peas, sweet corn and cereals. Those } \\
\text { have been found as a contaminant of } \\
\text { fruit, such as oranges and grapes etc. }\end{array}$ & $\begin{array}{l}\text { a. Blocks testosterone action } \\
\text { b. Reduce testosterone } \\
\text { synthesis } \\
\text { c. Anti-androgenic } \\
\text { properties }\end{array}$ \\
\hline Ketoconazole & $\begin{array}{l}\text { Ketoconazole is as an anti-fungal } \\
\text { product in pharmaceuticals to treat } \\
\text { fungal infections of the skin. }\end{array}$ & $\begin{array}{l}\text { a. Blocks testosterone action } \\
\text { b. Reduce testosterone } \\
\text { synthesis }\end{array}$ \\
\hline $\begin{array}{l}\text { Pyrethroid pesticides } \\
\text { Permethrin } \\
\text { Beta-cyfluthrin } \\
\text { Cypermethrin }\end{array}$ & $\begin{array}{l}\text { Some pyrethroid pesticides such as } \\
\text { Permethrin } \\
\text { beta-cyfluthrin, cypermethrin, are } \\
\text { still in use, with for example, the latter } \\
\text { found as a residue in apples, beans, } \\
\text { melons and oranges }\end{array}$ & $\begin{array}{l}\text { a. Blocks testosterone action } \\
\text { b. Reduce testosterone } \\
\text { synthesis } \\
\text { c. Anti-androgenic } \\
\text { properties }\end{array}$ \\
\hline
\end{tabular}


Common environmental Common uses and routes of exposure The effects on male

Toxicants

reproductive system

Certain sun-screens

4-MBC

3-BC
A few ultraviolet (UV) filters have been found as contaminants in waste water treatment plants and rivers.
Heat, Ionizing radiation, Non-ionizing radiation, microwaves, electromagnetic fields

Chemotherapeutic drugs (Cisplatin, cyclophosphamide, procarbazine, and doxirubicine, and vincristine etc.)
Mostly occupational exposures in home or industry as well as the mobile phone users.

Anticancer treatment. a. Estrogenic activity

b. Anti-androgenic activity

c. Interfere male sexual activity

d. delay male puberty

e. reduce reproductive organ weights in male offspring.

a. Testicular toxicity

b. Low sperm count and motility and density. c. Reduce male fertility d. Azospermia

a. Testicular dysfunctions

b. Low sperm count and motility and density. c. Infertility d. Azospermia and oligospermia.

\section{Identifying hazards}

A discrepancy exists between the number of chemicals in commerce (approximately 84,000) and the number that have been evaluated in model species for reproductive toxicity potential $(4,000)$ (U.S. EPA 1998a and 1998b). It is not feasible to allocate additional resources to test the 80,000 or so untested chemicals through traditional testing protocols, particularly given that about 2,000 new chemicals are introduced into commerce each year (U.S. EPA 1998). Instead, new, more rapid methods are needed to screen large numbers of chemicals and to identify those that are potential reproductive hazards. In the near term, top priorities will be to develop the most promising alternative models and to test their ability to appropriately classify the toxicity of sets of known toxicants and non-toxicants.

\subsection{High-throughput assays}

High-throughput assays evaluate the effect of a test substance on a single biologic process using an automated manner that allows thousands or tens of thousands of compounds to be tested in a short time at a reasonable cost. Robotics and genetic engineering make it possible to produce large quantities of receptors or genetically engineered cells for use in these assays. Knowledge about mechanisms of toxicity is often central to the strategy of highthroughput assays. For example, cells are being developed that are bioengineered to express human hormone receptors for estrogens and androgens. These cells can be used for highthroughput chemical screening for steroid hormone receptor affinity or the potential to act as endocrine disruptors. Both isoforms of recombinant human estrogen receptor and human androgen receptor are commercially available for this purpose. Based on the same principles, other batteries of high-throughput assays are available to screen for activity against various receptors and cytochrome P-450 enzyme isoforms (Lawson et al., 2003). The 
availability and application of these assays will undoubtedly expand as we understand more about the relevance of each protein in toxicologic processes.

\subsection{Structure-activity prediction}

Methods for predicting activity from structure continue to be developed and refined. Computer programs use available empirical information about the toxicity of existing compounds and their chemical characteristics to predict whether a new compound will have similar toxicity. These programs have not performed well in the area of reproductive and developmental toxicity, probably because reproductive processes are complex and effects may be elicited through multiple modes and mechanisms. As science progresses and we learn more about mechanisms of toxicity at the molecular level, however, structure-activity computer programs will become more exact and predictive. The best examples are the programs that are being developed and refined for estrogen receptor binding (Tong et al., 1997).

\subsection{Integration of human studies and tests of model species}

Though 4,000 chemicals have been tested in model species, few chemicals have been adequately evaluated for reproductive effects in humans and contain a partial list of known human developmental and adult toxicants. Because the interpretation of studies of model species is often not straightforward and because field studies are labor and resource intensive, a systematic approach is needed to select and prioritize chemicals for epidemiologic studies. Moorman et al., (2000) recently proposed a process for selecting chemicals for human field studies. In this process, information gained from model species testing conducted by the National Toxicology Program (NTP) was reviewed for significant adverse reproductive effects and potency of the toxicants. The evaluative process then combined this information with human exposure information available in public databases to arrive at a list of high-priority candidates for studies in humans.

\subsection{New biomarkers for humans and model species}

In 1977, men exposed to dibromochloropropane (DBCP), a pesticide that is now banned in the United States, were found to be azoospermic and oligospermic (Whorton et al., 1977). Currently, a variety of biomarkers are used to assess the potential adverse reproductive effects due to toxic chemical exposures. Bioindicators of sperm production and quality (semen volume, sperm concentration, sperm motility, sperm morphology) are routinely evaluated in ejaculated semen samples in men and in suspensions of epididymal sperm from test species (epididymal sperm reserves, sperm motility, and sperm morphology) (Moline et al., 2000; U.S. EPA 1998a). During the past decade, computer-assisted methods developed to improve and automate the evaluation of sperm motion and morphology have been added to the battery of routine sperm measures, and guidance for their use and interpretation has been made available through a number of workshops (ILSI 1999; Seed et al.,1996). Furthermore, baseline data on the relationship between various semen or epididymal sperm measures and fertility have emerged from a number of large studies designed to address this question (Zinaman et al.,2000). Thus, these measures are widely accepted biomarkers of adverse reproductive effects that are suitable for application in both human and model species studies. Serum hormone measures can also be determined in humans and test species. Inhibin B has been proposed as an indicator of testicular function 
and a possible surrogate for sperm measures (Anderson and Sharpe 2000). The recognition that sperm functional tests are also desirable has led to development of various new tests that have only recently been applied to toxicology. Biomarkers of the genetic integrity of sperm are designed to identify risks for paternally mediated developmental effects. Sperm proteins are being tested as biomarkers of fertility to detect specific deficits in sperm function (as opposed to decreased sperm output). Although details of such tests are beyond the scope of this review, Table 1. provides a list of new tests and references regarding methodology and examples of use. Further research is needed to make these tests more practical and more cost effective and to determine their ultimate utility for hazard identification and elucidation of modes and mechanisms of toxicant action.

$\begin{array}{lll}\text { Target } & \text { Bioassay } & \text { Function assessed } \\ \text { Sperm fertilizing ability } & \begin{array}{l}\text { SP-22 protein } \\ \text { Sperm antigens } \\ \text { Ubiquitin } \\ \text { Cytoplasmic droplets } \\ \text { Sperm maturity }\end{array} & \begin{array}{l}\text { Sperm function } \\ \text { Acrosome reaction }\end{array} \\ & \begin{array}{l}\text { Sperm morphology } \\ \text { CMA3 staining }\end{array} & \\ \text { COMET } & \text { CNA adducts } & \text { Chromatin damage } \\ \text { Sperm DNA } & \text { TUNEL } & \text { DNA damage } \\ & \text { SCSA } & \text { Aneuploidy, Brakage } \\ \text { Sperm chromosomes } & \text { FISH } & \begin{array}{l}\text { Translocation } \\ \text { Endocrine feedback of } \\ \text { spermatogenesis. }\end{array}\end{array}$

Abbreviations: CMA3 staining, Chromomycin A3 staining; COMET, Single-cell gel electrophoresis assay; FISH, Fluorescence in situ hybridization; SCSA, Sperm chromatin structure assay; TUNEL, Terminal deoxynucleotidyl transferase-mediated dUTP-biotin end-labeling (Lawson et al., 2003)

Table 1. The Biomarkers for the assessment of male reproductive toxicity by Chemical agents (Lawson et al., 2003).

\subsection{Estimating occupational exposure}

Establishing that a significant number of workers or members of the general population are or will be exposed to a potential reproductive toxicant is central to priority setting. NIOSH's National Occupational Hazard Survey and National Occupational Exposure Survey conducted in 1972-1974 and 1981-1983, respectively, has been used extensively to identify substances of common exposure (NIOSH 1978, 1988). These surveys are the only comprehensive assessments of general industry where the number of workers potentially exposed to chemical agents has been estimated. However, these databases are outdated and of limited use because they indicate only potential exposure. NIOSH is currently planning a new hazard surveillance activity that will target industry sectors on a rolling basis, beginning with the health care sector. Public health researchers will continue to require updated exposure surveys to keep up with the changing workplace exposures and monitor 
new exposures that may be potential reproductive toxicants. New technologies such as geographic information systems (GIS) allow mapping of industries and specific chemical exposures. Use of GIS to identify geographic areas with high volume of use of suspect chemicals might be an effective method of identifying populations with greater potential occupational and environmental exposures. Biomonitoring is a valuable tool for estimating occupational exposure. The National Report on Human Exposure to Environmental Chemicals is a new and ongoing assessment of the U.S. population's exposure to environmental chemicals. The first edition of the report presents levels of 27 environmental chemicals, including metals (e.g., lead, mercury, and uranium), cotinine (a marker of tobacco smoke exposure), organophosphate pesticide metabolites, and phthalate metabolites. This is a significant step forward in assessing the potential human toxicity of a class of chemicals known to be reproductive and developmental toxicants in rodents. Improved methods for analysis of exposure, especially of age and time effects, are likely to impact the characterization of occupational exposure in these studies (Richardson and Wing 1998). Current research approaches usually consider the action of single, unique toxicants on outcomes of interest, creating yet another challenge to drafting a reproductive hazards agenda. The more common human exposure scenario is to mixtures of toxicants at low concentrations, episodically and over the long term. Attention to cumulative exposure over years of a working lifetime and total aggregate exposure to toxicants from multiple exposure sources, as well as classical considerations of exposure routes, must also be addressed. Methodologic approaches must enlarge and mature to consider the effects and modulation of effects mediated by both exposure to mixtures of toxicants and the complexities of exposure mode at low dose and over prolonged duration.

\subsection{Mechanistic research}

Understanding mechanisms of action of toxicants is important for a number of reasons, including a) supporting the biologic plausibility of an observed association between chemical exposure and adverse outcome; $b$ ) uncovering common pathways of actions of different agents; $c$ ) extrapolating across species for risk assessment; $d$ ) improving the predictability of human morbidity from responses of model species; and e) predicting responses to mixed exposures (Lawson et al., 2003). Mechanistic studies are not new in toxicology; however, new tools in genomics, proteomics, and bioinformatics present unprecedented opportunities to advance our understanding of toxicant action at a molecular level. Genomic information and the ability to screen most or all of the genome of an increasing number of organisms for changes in gene expression are revolutionizing the way in which biologic effects data are gathered. It is now possible to determine the effects of a toxicant exposure on gene expression of most of the genome of mice and rats. This will allow us to generate testable hypotheses about the mechanism of action of toxicants. It will also open up the possibility of identifying markers of exposure or effect specific to a particular insult that can be used in field studies. As with any new technology, a number of problems will need to be overcome for the promise of genomics to be realized. The first will be to manage the large volume of information produced by gene expression experiments. Gene chips may contain thousands or tens of thousands of sequences. Experience shows that any perturbation in a biologic system leads to numerous changes in gene expression. An entire field of bioinformatics is being developed to help collect, organize, and manage 
the data to identify changes related temporally, by dose, or by metabolic pathway. The second challenge will be to separate those changes in gene expression pivotal to the toxic response from those that are more generalized responses to any stimulus. The third challenge will be to quantitatively relate changes in expression of critical genes with toxicity, which is manifested at a more complex level of biologic organization (i.e., the cell, organ, or organism). Real comfort in this genomic approach will come only with experience and the development of a large database.

\subsection{Gene-environment interactions}

Reproductive toxicants can affect human populations over the total life span, including the in utero and perinatal periods, childhood, puberty, and adulthood. Thus, extending research efforts to address stage-specific sensitivity is recommended. Another emerging approach allows the identification of populations at potentially increased risk from toxicant exposure by characterizing genetic polymorphisms of metabolizing enzymes in exposed cohorts. Such methods may identify vulnerable subpopulations on the basis of inherent (genetic) differences in their ability to metabolize a toxicant.

\subsection{Identifying genes that increase sensitivity to reproductive toxicants}

Genetic factors that elevate risk for disease can be grouped into two categories: those for which having a particular allele conveys a high risk for the disease regardless of other (e.g., environmental) influences and those associated with only small increases in risk of the disease. The latter, termed susceptibility genes are being identified at an increasing rate. The interaction of these alleles with environmental agents or other susceptibility alleles ultimately determines whether the disease will be manifested. Much work has been done to understand the role of these genes for reproductive toxicity.

\subsection{Potential information from genetics to advance epidemiologic studies}

If epidemiologic studies could identify genetic-toxicant interactions by comparing the prevalence of a particular genetic marker (polymorphism) or a group of markers in affected and unaffected populations, this information could be used to target environmental, behavioral, or medical interventions (Khoury 1997). Ultimately, validation of genetic testing to link a particular genotype with exposure to a specific chemical to the increased prevalence of a particular reproductive disorder would require epidemiologic confirmation (Khoury \& Dorman 1998).

\subsection{Communication}

An essential component of future reproductive studies will be improved communication. Because of the complex mechanisms involved in reproductive research, collaboration across scientific disciplines must be conducted. In addition, notification of research results and recommendations must be communicated to workers and the affected public in a manner that is timely, accessible, and easily understood. A primary goal of reproductive research is to reduce the high percentages of adverse outcomes such as infertility, pregnancy loss, and congenital malformations. Although certain limitations exist that are unique to reproductive research, many advances in technology and methodologies have been recently developed that will aid researchers in their efforts to a) understand mechanisms by which toxicants 
exert their effects, b) identify populations at risk, and c) evaluate reproductive and developmental hazards to improve public health.

\section{Methods of assessing male reproductive capacity}

The determination of sperm concentration, morphology, and motility remains the primary clinical assay for male infertility (WHO, 1999). The WHO guidelines on semen quality provide reference semen parameters as follows: sperm concentration $>20$ million $/ \mathrm{ml}, 50 \%$ motility, and at least 50\% normal morphology (WHO, 1999). Oligospermia is the term for semen with $<20$ million/ $\mathrm{ml}$ sperm in ejaculate, and asthenospermia for semen with sperm $<50 \%$ motility or $<25 \%$ rapid progressive motility, teratospermia for reduced percent sperm with normal morphology, and azoospermia for the absence of sperm in the ejaculate (Braude \& Rowell, 2003). It is unknown whether endocrine disrupter exposure represents a subset of the environmental risk factors for male infertility, as there are few studies that examine exposure and human semen quality. Moreover, toxicants can affect the male reproductive system at one of several sites or at multiple sites. These sites include the testes, the accessory sex glands, and the central nervous system, including the neuroendocrine system.

\subsection{The contribution of experimental models}

The usefulness of experimental animal models is usually perceived as limited to hazard identification using the test protocols specified by regulatory agencies. However, animal models can also provide valuable support to reproductive risk assessment on many other fronts. If the focus is on human exposure, animal studies can be designed to confirm reproductive toxicity when initial observations in exposed humans are suggestive of an adverse effect. Furthermore, such observations can be extended across a wide range of exposures in animals, using any route of exposure and any specified dose versus time scenario. For example, when human exposure is likely to be acute or intermittent, animal models are ideal for defining critical exposure windows based on developmental stage or for revealing the pathogenesis of an effect at various times after exposure through recovery. This is particularly important with respect to male reproductive effects because alterations in semen quality or fertility may not become evident until sometime after the exposure, particularly if an early stage of spermatogenesis is targeted. A rodent model is most commonly used for the study of reproductive and developmental toxicity (Claudio et al., 1999). To use toxicology data derived from animal studies to advantage in risk assessment, it is critical to identify and understand species-specific differences in physiology and metabolism that may affect the response to the toxicant in question. Rodent models have, for example, been used to determine the relationship between sperm end points and function (fertility) (Chapin et al., 1997). Determining that a substance is toxic to the male reproductive system is only the first step: The next step is to examine its mechanisms of toxicity. Mechanistic information allows for predictions about the potential toxicity of individual compounds or complex mixtures in humans, for better understanding of the windows of vulnerability in the development of the male reproductive system, and for developments of possible preventive or curative measures. Acute short-term exposure models combined with serial exposure models give a complete picture of the range of effects (Claudio et al., 1999). Exposing animals over a long period of time allows for the detection of transgenerational effects from chemicals, such as male-mediated developmental effects. If developmental 
effects appear, researchers can go back and administer a dose during that critical period of development to refine knowledge about how such problems occur. Early developmental end points measurable in animal research include anogenital distance at birth, testis position, genital malformations, secondary sex characteristics, and serum hormone levels. Acute short-term exposures, on the other hand, can be useful for identifying critical windows of exposure. Acute exposures followed over time can help identify the pathogenesis of a lesion, isolate the cell type that is susceptible to damage (germ cells, spermatocytes, or spermatid), and determine genetic effects, including the repair capability of affected genes. Serial sacrifice studies are best used for identifying the earliest detectable pathologic changes in target organs, cells, or processes. Multigeneration studies, in particular continuous breeding studies, yield the most thorough assessment of the many complex processes that result in reproductive and developmental toxicity.

\subsection{Epidemiologic approaches}

Epidemiologic methods for assessing the impact of hazardous substances on male reproductive health include $a$ ) questionnaires to determine reproductive history and sexual function, $b$ ) reproductive hormone profiles, and $c$ ) semen analysis. The choice of appropriate methodologies to study the effects of reproductive toxicants is predicated on the investigators' understanding of several factors: the nature of the exposed population; the source, the levels, and the known routes of exposure; the organ systems in which a toxicant exerts its actions; the hypothesized mechanisms of a toxicant's actions; and the techniques available to assess the effects of toxicants in the relevant organ systems (Wyrobeck et al., 1997). Table 2 outlines the methods currently available for assessing the principal targets of male reproductive toxicants in humans--the testes, the accessory sex glands, the neuroendocrine system, and sexual function. Researchers and clinicians interested in male reproductive health and fertility are using increasingly sophisticated methods adapted from the fields of assisted reproductive technology and reproductive toxicology, including assays of sperm function, genetic integrity, and biomarkers of DNA damage. For population-based studies involving occupational groups or communities with environmental exposures, issues related to the cost, validity, precision, and utility of these methods must be carefully considered.

The testis, the site of sperm cell production and the target organ for genetic damage, is most often studied. To establish the extent of toxicity to the testis, researchers can measure the size of the testis, obtain a semen sample, or take a testicular biopsy. Standard semen analyses (including semen volume, sperm concentration, total sperm count, motility, and morphology) have been the primary research tools for studying the effects of toxicants on the male reproductive system. Epidemiologic studies have successfully utilized semen quality as a marker of fertility (Fisch et al., 1997). The uncertainties associated with traditional semen measures have led to the recent development of assays of sperm function and genetic integrity; these assays may prove more sensitive and more specific reflections of toxicant-induced effects (e.g., aneuploidy or reduced sperm motility) in individuals (Martin et al., 1997). However, The accessory sex glands, which include the epididymis, prostate, and seminal vesicle, may also be targets of toxicants (Schrader, 1997). Ethylene dibromide is one substance that affects the accessory sex glands after occupational exposure. Alterations in sperm viability, as measured by eosin stain exclusion or by hypo-osmotic swelling or alterations in sperm motility variables, suggest a problem with the accessory sex glands. Biochemical analysis of seminal plasma provides insights into glandular function by 
Sl. No. Methods of Assessment:

1. Testosterone (T), Prolactin, LH, FSH, and Inhibin-B concentrations.

2. Semen volume and $\mathrm{pH}$.

3. Sperm density/Sperm count.

4. Sperm morphology and morphometry

5. Sperm motility (\% of motile and velocity), Sperm viability (Vital stain and Hyper Osmotic Swelling (HOS)).

6. Sperm function assays (Acrosome reaction, Hemizona assay of sperm binding and sperm penetration assay).

7. Sperm genetic analysis (Sperm chromatin stability assay, Comet assay. Assessment of chromosomal aneuploidy and Nuclear microdeletions).

8. Marker chemicals from accessory glands (Epididymis is represented by glycerylphosphorylcholine, Seminal vesicles by fructose, and the Prostate gland by zinc).

9. Nocturnal penile measurements.

10. Personal reproductive history (Pubertal development, Paternity (Pregnancy timing and outcomes), Sexual functions (Erection, Ejaculation, Orgasm and Libido)).

Table 2. Assessment of Male Reproductive Capacity in Humans (Moline et al., 2000).

evaluating marker chemicals secreted by each respective gland (Schrader, 1997). For example, the epididymis is represented by glycerylphosphorylcholine, the seminal vesicles by fructose, and the prostate gland by zinc. Measures of semen $\mathrm{pH}$ and volume provide additional general information on the nature of seminal plasma, reflecting post testicular effects. A toxicant or its metabolite may act directly on accessory sex glands to alter the quantity or quality of their secretions. Alternatively, the toxicant may enter the seminal plasma and affect the sperm or may be carried to the site of fertilization by the sperm and affect the ova or conceptus. The presence of toxicants or their metabolites in seminal plasma can be analyzed using atomic absorption spectrophotometry or gas chromotography/mass spectrometry. Impact on the neuroendocrine system is another mechanism whereby toxicants can disturb the male reproductive system. To establish the extent of endocrine dysfunction, hormone levels can be measured in blood and urine. The profile recommended by NIOSH to evaluate endocrine dysfunction associated with reproductive toxicity consists of assessing serum concentrations of follicle-stimulating hormone (FSH), luteinizing hormone (LH), testosterone, and prolactin (Schrader, 1997). Because of the pulsatile secretion of $\mathrm{LH}$, testosterone, and to a much lesser extent $\mathrm{FSH}$, and the variability in the evaluation of reproductive hormones, it is recommended that three blood samples be drawn at set intervals in the early morning and the results pooled or averaged for clinical assessment. In epidemiologic field studies, however, multiple blood samples are impractical and may decrease participation rates. Alternatively, LH and FSH can be measured in urine, providing indices of gonadotropin levels that are relatively unaffected by pulsatile secretion. However, if an exposure can affect hepatic metabolism of sex steroid hormones (Apostoli et al., 1996), urinary measures of excreted testosterone metabolite (androsterone) or estradiol metabolite (estrone-3-glucuronide) are not recommended. Moreover, future assessment of reproductive hormones may extend to inhibin, activin, and follistatin, polypeptides that are 
secreted primarily by the gonads and that act on the pituitary to increase (activin) or decrease (inhibin and follistatin) FSH synthesis and secretion. Within the gonads, these peptides regulate steroid hormone synthesis and may also directly affect spermatogenesis. Ongoing studies are investigating the utility of serum inhibin-B level as an important marker of Sertoli cell function and in utero developmental toxicity (Jensen et al., 1997). Other indicators of central nervous system toxicity are reported alterations in sexual function, including libido, erection, and ejaculation. There is not much literature on occupational exposures causing sexual dysfunction in men (Schrader, 1997); however, there are suggestions that lead, carbon disulfide, stilbene, and cadmium can affect sexual function. These outcomes are difficult to measure because of the absence of objective measures and because sexual dysfunction can be attributed to and affected by psychologic or physiologic factors (Schrader, 1997).

\subsection{Biomarkers of genetic damage}

Biomarkers of chromosomal and genetic damage are increasingly used in the search to understand abnormal reproductive health outcomes, in part because of the possibility that there may be identifiable genetic polymorphisms which make an individual more susceptible to the adverse reproductive effects from exogenous substances. These assays provide promising and sensitive approaches for investigating germinal and potentially heritable effects of exposures to agents and for confirming epidemiologic observations on smaller numbers of individuals. Efficient technology for examining chromosomal abnormalities in sperm has only been developed recently. Chromosomal abnormalities are primarily of two types: numerical and structural. Both kinds can be attributed in some cases to paternal factors. Karyotype studies have shown that although oocytes demonstrate a higher frequency of numerical chromosomal abnormalities, human sperm demonstrate a higher frequency of structural abnormalities with less frequent numerical abnormalities (Moosani et al., 1995). In assessing sperm exposure to toxicants, it is therefore imperative to assess DNA structural integrity and not just chromosomal count. Aneuploidy is a chromosomal abnormality that causes pregnancy loss, perinatal death, congenital defects, and mental retardation. Aneuploidy, a disorder of chromosome count, is observed in approximately 1 in 300 newborns. It is speculated that of all species, humans experience the highest frequency of aneuploidy at conception, with estimates ranging from 20 to $50 \%$ (Moosani et al., 1995). Spontaneous abortions occur in at least $10-15 \%$ of all clinically recognized pregnancies. Of these, 35\% contain chromosomal aneuploidy. Despite such a high frequency, there is little information about what causes this abnormality in humans. Paternal origins of aneuploidy and other genetic abnormalities can be analyzed by studying chromosome complements in human sperm. Two types of analyses provide data on chromosomal abnormalities in human sperm: sperm karyotype analysis and fluorescence in situ hybridization (FISH) (Moosani et al., 1995). Each technique has advantages and disadvantages. Sperm karyotyping is performed after sperm have fused with hamster oocytes. It provides precise information on numerical and gross structural abnormalities of all chromosomes from a given spermatozoon. However, only a limited number of sperm can be evaluated in each assay, and only those sperm that fertilize the oocytes are analyzable. Furthermore, this assay is technically difficult, labor intensive, expensive, and requires the use of animals. Also, it is better suited for clinical than for field studies because it must be performed on fresh semen. FISH, on the other hand, relies on the use of chromosomespecific probes to detect extra chromosomes (aneuploidy) or chromosome breaks or 
rearrangements in sperm. It is performed directly on sperm cells, eliminating the need for the use of animals. Although information is gained only for several chromosomes at a time, slides can be reprobed to increase the number of chromosomes evaluated. Furthermore, FISH can be conducted on archived sperm (either frozen or dried on slides), making it ideal for use in field studies. However, because the incidence of sperm aneuploidy is low, many cells (up to 10,000 per semen sample) must be evaluated, which requires significant scoring times. In comparison to karyotype analysis, however, FISH is relatively inexpensive and technically simpler, and data are obtained on all sperm, not just the ones that are capable of fertilization. These two techniques complement each other, with FISH providing information on large numbers of cells and karyotyping providing more precise and detailed information (Robbins et al., 1997).

\subsection{Develop biomarkers of exposures and male reproductive health for research and clinical use}

Resources must be invested in developing more advanced biomarkers of exposure to reproductive toxicants and of male reproductive health outcomes. Advanced biomarkers would allow for the development of toxicant-specific tests (e.g., polycyclic aromatic hydrocarbon-DNA adducts) and the detection of subclinical changes that might have significant health implications but which now go unnoticed by current measures. New biomarkers of semen quality are advantageous in that they can both describe male reproductive capacity and indicate toxic effects independent of the female partner's reproductive health. New tests could more accurately measure sperm function, fertilization potential, and the transmission of an intact male genome. Genetic testing may provide valuable tools for researchers and clinicians. For example, the sperm chromatin stability assay and FISH are used to assess genetic structure after exposure to a potential toxicant. Recently, single nucleotide polymorphisms have been used in the assessment of geneenvironment interactions.

\section{Mechanism of male reproductive toxicity}

The disruption of spermatogenesis may be represented by four mechanisms, including (1) epigenetic changes to the genome, (2) apoptosis of germ cells, (3) dysregulation of androgenic signaling, and (4) disruption of Sertoli and other spermatogenesis support (Phillips \& Tanphaichitr, 2008) (Figure 4). The first mechanism is relatively novel and was only demonstrated in vitro by one group thus far. Rats exposed in vitro to anti-androgenic pesticides vinclozolin or methoxychlor demonstrated heritable changes in methylation status of genomic DNA. These epigenetic effects included impaired male fertility and were evident in the F3 and F4 generations (Anway et al., 2005). Reduced sperm number or altered sperm morphology may be indicative of problems during spermatogenesis and spermiogenesis and may be produced by the direct loss of developing spermatocytes. Adult rats exposed in utero to flutamide, an antiandrogen, exhibit hypo-spermatogenesis associated with increased apoptosis of adult germ cells (Maire et al., 2005). Anti-androgenic exposure is associated with elevation of pro-apoptotic molecules, including Fas-L (Maire et al., 2005), caspase- 3 and caspase-6, Bax, Bak, and Bid, and a decrease in anti-apoptotic molecules Bcl2 and Bclw (Bozec et al., 2004) in rat models. Di(2-ethylhexyl) phthalate (DEHP) exposure in rats induces testicular apoptosis via a mechanism involving ERK1/2induced up-regulation of PPAR (peroxisome proliferators-activated receptor) $-\gamma$, RXR 


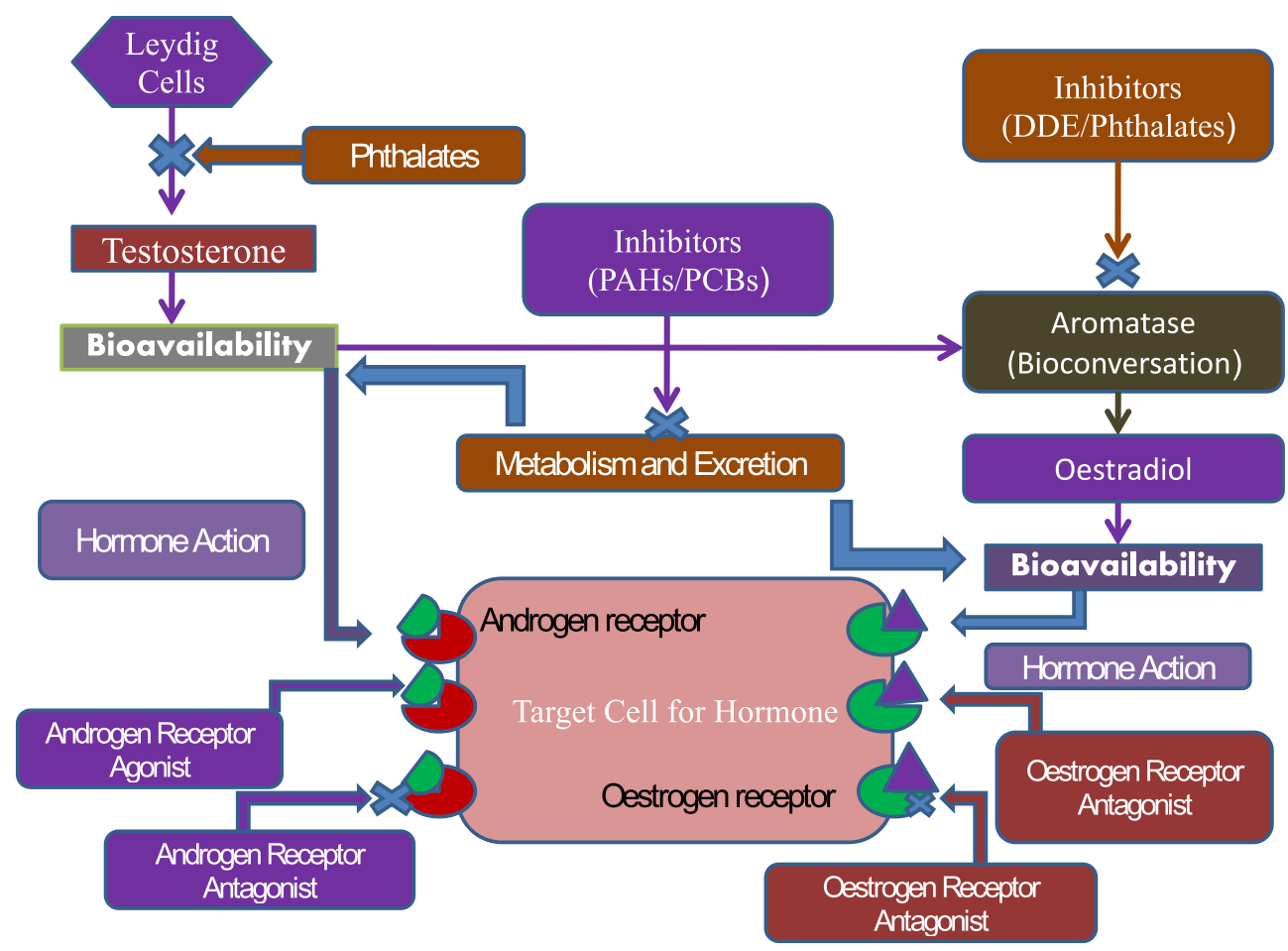

Fig. 4. Possible Pathways of endocrine disruption by environmental chemicals. DDE=1, 1dichloro-2, 2-bis (p-chlorophenyl) ethylene; DDT= dichlorodiphenyltrichloroethane; $\mathrm{PAHs}=$ polycyclic aromatic hydrocarbons; $\mathrm{PCBs}=$ polychlorinated biphenyls. (Modified from Sharpe \& Irvine, BMJ, 2004).

(retinoid X receptor)- $\mathrm{a}$ and $\mathrm{p} 21$, and down-regulation of $\mathrm{pRB}$, cyclin $\mathrm{D}, \mathrm{CDK} 2$, cyclin $\mathrm{E}$, and CDK4 (Ryu et al., 2007). Neonatal estrogen treatment (DES, ethinyl estradiol [EE]) increased apoptosis at all stages of spermatogenesis in the rat (Atanassova et al., 1999). Thus, apoptosis is a likely mechanism for some mechanisms of endocrine disruption in the testis (Jana et al., 2010b). Testicular androgenic signalling may be impaired via several mechanisms, including decreased Leydig cell population, impaired Leydig cell steroidogenesis, and dysregulation of the HPT axis. Abnormal development and maturation of the Leydig cell population reduces the steroidogenic potential of the testis. In utero exposure to phthalate esters is associated with morphological abnormalities of the male reproductive tract, including decreased anogenital distance, cryptorchidism, hypospadias, diminished Leydig cell population, and decreased testicular testosterone (Mylchreest et al., 2000; Fisher et al., 2003). Phthalate esters such as DEHP are proposed to exert antiandrogenic and estrogenic mechanisms of action and disrupt hormone synthesis via an AhR pathway (Ge et al., 2007). Low-dose BPA exposure in utero reduced the size of the epididymis and decreased anogenital distance and increased prostate size (Gupta, 2000) in adult mice. Leydig cell maturation and development include expression of genes related to endocrine signaling (LH receptors, AR) and steroidogenesis. Steroidogenesis is dependent 
on availability of cholesterol to the cytochrome P-450 cholesterol side chain cleavage (P450scc) enzyme complex within the mitochondria, the rate-limiting and regulated step in steroidogenesis (Miller, 1988). Steroidogenic acute regulatory protein (StAR) is proposed as the candidate protein for the acute regulation of steroidogenesis. StAR transports cholesterol into the inner membrane, where steroidogenic enzymes catalyze consecutive reactions to convert cholesterol to testosterone in Leydig cells (Clark et al., 1994, Jana et al., 2008; 2010a; 2010b). In utero exposure to exogenous estrogens (EE, DES, genistein, and BPA)

downregulate expression of a number of testicular genes including Cyp17, Cyp11a, and StAR expression in the rat and mouse (Fielden et al., 2002). The expression of a number of genes related to steroidogenesis (Scarb1, Star, Cyp11a1, HSD3b1, and CYP17a1) was altered following in utero exposure to $\operatorname{di}(n$-butyl) phthalate (Barlow et al., 2003). Testicular androgen signalling may also be impaired through suppression of normal HPT regulation of Leydig cell steroidogenesis. Disruption of the HPT axis, thereby reducing testicular testosterone levels, was demonstrated in the rat following exposure to a range of endocrine disrupters. Exposure to estrogens DES and EE also impaired HPT signalling in the rat, reducing plasma testosterone and increasing plasma FSH (Atanassova et al., 1999). Both Leydig and Sertoli cells contain the enzyme aromatase and convert androgens to estrogens, thereby providing an intratesticular source of estrogens (O'Donnell et al., 2001). Atrazine, a herbicide with antiandrogenic and estrogenic properties, was found to produce a number of adverse reproductive effects in the rat. Atrazine has a low affinity for androgen and estrogen receptors, reduces androgen synthesis, and enhances estrogen production via the induction of aromatase (Sanderson et al., 2000). Thus, testicular physiology is sensitive to perturbations of androgenic and estrogenic signalling, such that xenobiotic exposures might result in reduced fertility. Sertoli cell number is directly representative of the spermatogenic potential of the testis. Ablation of the Sertoli cell population, or loss of Sertoli cell function, is therefore another mechanism by which endocrine disrupters may impair spermatogenesis. Exposure to prenatal DES or EE reduced adult population of Sertoli cells in rats (Atanassova et al., 1999) and supports the hypothesis that in utero exposure to estrogens contributes to impaired spermatogenesis in the adult. It is also noteworthy that human spermatogenesis is much less efficient than in rodents, such that small decreases in the population of Sertoli cells would be expected to have large effects on male fertility in human. Estrogenic disruption of the testis is perhaps the most well characterized example of endocrine disruption of spermatogenesis; however, it is also worthy to note that estrogens play important roles in development of hormone responsive tissue, including Leydig cells and development and differentiation of the fetal male reproductive tract (Tsai-Morris et al., 1986). ERs, both alpha and beta (ERa and ERß), are found throughout the male reproductive tract and represent a transcriptional mechanism by which endocrine disrupters may alter gene expression. In rodents, ERa is expressed by all developmental stages of Leydig cells (fetal, neonatal/pubertal/adult), seminiferous tubules, efferent ductules, and epididymis but not Sertoli cells. ERß is expressed in all stages of rodent Leydig and Sertoli cell development and in efferent ductules and epididymis (O'Donnell et al., 2001). The existence of plasma membrane ERs along with the different tissue distribution, C-terminal ligandbinding domain and N-terminal transactivation domain of ERa and ERß provide possible explanations for the differential effects of so-called weak estrogens like BPA (Wozniak et al., 2005). These are but a few of the mechanisms by which endocrine disrupters might impair spermatogenesis. Other mechanisms include dysregulation of bioavailable androgens via 
increased synthesis of sex hormone binding globulin (SHBG) and other plasma binding proteins (Haffner, 1996) and disruption of testicular androgen signaling by AhR ligands, PAH and nicotine, contained in tobacco smoke (Kizu et al., 2003) and many others. Further that, increasing evidence suggests an induction of oxidative stress in the testis represents another common response after exposure to environmental toxicants (Jana et al., 2010a \& $2010 \mathrm{~b}$ ). Increase in oxidative stress can be seen in $\leq 80 \%$ of clinically proven infertile men, and exposure to environmental toxicants is a major factor contributing to such an increase (Tremellen, 2008). Environmental toxicants that have been shown to induce oxidative stress in the testis are highly heterogeneous, with different chemical structures, and include cadmium (Liu et al., 2009), bisphenol A (Kabuto et al., 2004) and 2,3,7,8-tetrachlorodibenzop-dioxin (Dhanabalan \& Mathur, 2009).

Interestingly, these environmental toxicants commonly increase oxidative stress by down regulating the production of antioxidant enzymes such as superoxide dismutase, catalase and glutathione peroxidase. In turn, excessive amounts of reactive oxygen species (ROS) are produced. ROS damage the lipids, proteins, carbohydrates and DNA in cells (Jana et al., 2010a \& 2010b; Figure 5). Importantly, these observations were confirmed in studies illustrating that co-administration of antioxidants such as vitamin $\mathrm{E}$ with environmental toxicants could alleviate the pathophysiological effects (e.g. reduction in sperm count) of toxicants in the testis (Latchoumycandane \& Mathur, 2002). These findings demonstrate that oxidative stress induced by environmental toxicants is one of the major contributing factors to male infertility. In fact, oxidative stress has long been linked to male infertility; although most studies have focused on its roles in causing abnormalities in germ cells and apoptosis (Sikka, 2001; Turner and Lysiak, 2008). Recent studies have shown that environmental toxicant-induced oxidative stress can cause male infertility by disrupting the cell junctions and adhesion between Sertoli-Sertoli cells and/or Sertoli-germ cells via the phosphatidylinositol 3-kinase (PI3K)/c-Src/focal adhesion kinase (FAK) signaling pathway (Wong \& Cheng, 2011). Oxidative stress is known to increase epithelial and endothelial permeability by disrupting tight junctions (TJ) and adherens junctions (AJ) between cells (Sandoval and Witt, 2008). Activation of the PI3K/c-Src signalling pathway in response to oxidative stress induced by environmental toxicants could be a common mechanism by which the toxicants trigger damage to the testis. Early evidence shows that the toxic effects of 2,3,7,8-tetrachlorodibenzo-p-dioxin in the testis are caused by an induction in c-Src kinase activity. Furthermore, significant increase in the c-Src level has also been detected in the testis after cadmium exposure in rodents, indicating that c-Src is activated in response to multiple environmental toxicants (Wong et al., 2004; Wong \& Cheng, 2011) (Figure 6).

The MAPK pathways have emerged as a common signaling platform for multiple environmental toxicants (Figure 6). Three MAPKs (extracellular-signal-regulated kinase (ERK), c-Jun N-terminal kinase (JNK) and p38) have been shown to be activated in the testis after exposure to environmental toxicants. MAPKs are involved in regulating normal reproductive functions in the testis, which include spermatogenesis (e.g. cell-cycle progression, meiosis, BTB dynamics, cell adhesion dynamics and spermiogenesis), steroidogenesis, sperm hyperactivation and acrosome reaction (Almog \& Naor 2010). As a result, unregulated activation of MAPKs by environmental toxicants imposes an array of pathophysiological effects on Sertoli cells, germ cells and Leydig cells in the testis. These include an increase in DNA damage and apoptosis, disruption of cell junctions and steroidogenesis (Li et al., 2009; Wong \& Cheng, 2011). MAPKs are activated by oxidative 
stress induced by environmental toxicants in cells and tissues. For example, blocking oxidative stress by free-radical scavengers (e.g. N-acetyl cysteine), reverses cadmiuminduced MAPK activation (Chen, et al., 2008). This phenomenon is partly regulated by the inhibition of Ser/Thr protein phosphatases 2A (PP2A) and 5 (PP5) by oxidative stress, which results in an increase in phosphorylation of MAPK (Chen, et al., 2008). In addition, activation of ERK can lead to phosphorylation of c-Src, FAK and paxillin under oxidative stress, implying that MAPKs might be one of the upstream targets to activate these nonreceptor tyrosine kinases (Li et al., 2009) (Figure 6). Activation of MAPKs by environmental toxicants also upregulates the expression of proinflammatory cytokines such as nuclear factor $k B(N F k B)$, and tumor necrosis factor-a (TNFa) in macrophages and monocytes (Lecureur et al., 2005), which can diffuse from microvessels in the interstitial space and disrupt the BTB because they are known to perturb the Sertoli cell TJ-permeability barrier (Li et al., 2009). Similarly, cadmium and pollutants from motorcycle exhausts (e.g. polycyclic aromatic hydrocarbons) increase the expression of transforming growth factor- $\beta$ (TGF- $\beta$ ) and interleukin-6 (IL-6) in the testis, respectively (Lui et al., 2009). TNFa, TGF- $\beta$ and IL-1 $\alpha$ are known to disrupt Sertoli-Sertoli and Sertoli-germ cell junctions via downregulation (Li et al., 2006) and/or redistribution of junctional proteins (Wong \& Cheng, 2005) such as occludin, ZO-1 and N-cadherin in the seminiferous epithelium. Consequently, the loss of integral membrane proteins at the cell-cell interface causes disruption of the BTB and adhesion of germ cells in the seminiferous epithelium, which lead to the premature release of germ cells from the epithelium and hence infertility (Li et al., 2006; Li et al., 2009; Wong \& Cheng, 2011). Furthermore, proinflammatory cytokines (e.g. IL-6 and TNFa) activate leukocytes to produce ROS, which amplifies the deleterious effects of environmental toxicant-induced oxidative stress (Tremellen, 2008). The male reproductive system has emerged as one of the major targets of environmental toxicants. Although acute exposure to toxicants contributes to apoptosis and the necrosis of testicular cells, chronic and sub-lethal exposure is prevailing in the general public (Hauser \& Sokol 2008). Due to the unusually long half-lives of some of these toxicants in the mammalian body (e.g. cadmium has a mean half-life of $>15$ years), chronic and low-level exposure to humans could cause long-term unwanted health effects. The disruptive effects of environmental toxicants on cell junctions mediated by non-receptor tyrosine kinases (e.g. c-Src and FAK) and cytokines through oxidative stress because such damage is often observed in low-level exposure before apoptosis occurs (Li et al., 2006; Li et al., 2009). Significantly, these signalling pathways converge to utilize polarity proteins to regulate intercellular junctions. Polarity proteins (which are known to control cell adhesion in the testis) thus emerge as novel targets for therapeutic intervention to limit environmental toxicant-induced infertility. Although it is equally important to study the epigenetic (e.g. vinclozolin) and endocrine-disruptive (e.g. BPA, dioxin, cadmium) effects of environmental toxicants, it is increasingly clear that these toxicants are imposing an immediate deleterious effect in the testis via disruption of cell junctions between testicular cells due to increase in oxidative stress. In addition, endocrinedisrupting toxicants that affect estrogen levels might cause a disturbed balance of ROS and oxidative stress because estrogen is an important free-radical scavenger in humans, besides being essential for spermatogenesis (Carreau and Hess, 2010).

Recent studies have emphasized the importance of assessing the effects of a mixture of environmental toxicants on male reproductive function because humans are exposed to an array of chemicals that might antagonize or agonize each other (Hauser \& Sokol 2008). 
Although this type of study is inherently difficult to undertake, it is crucial for a full understanding of the impact of environmental toxicants on the reproductive system. However, much work is needed to understand the precise molecular events and mechanism(s) regulated by environmental toxicants to target c-Src, FAK, MAPK and polarity proteins in the testis. Only then can we identify specific phosphorylation targets or isoforms so that small-molecule agonists and/or antagonists can be designed to limit systemic toxicity in vivo.

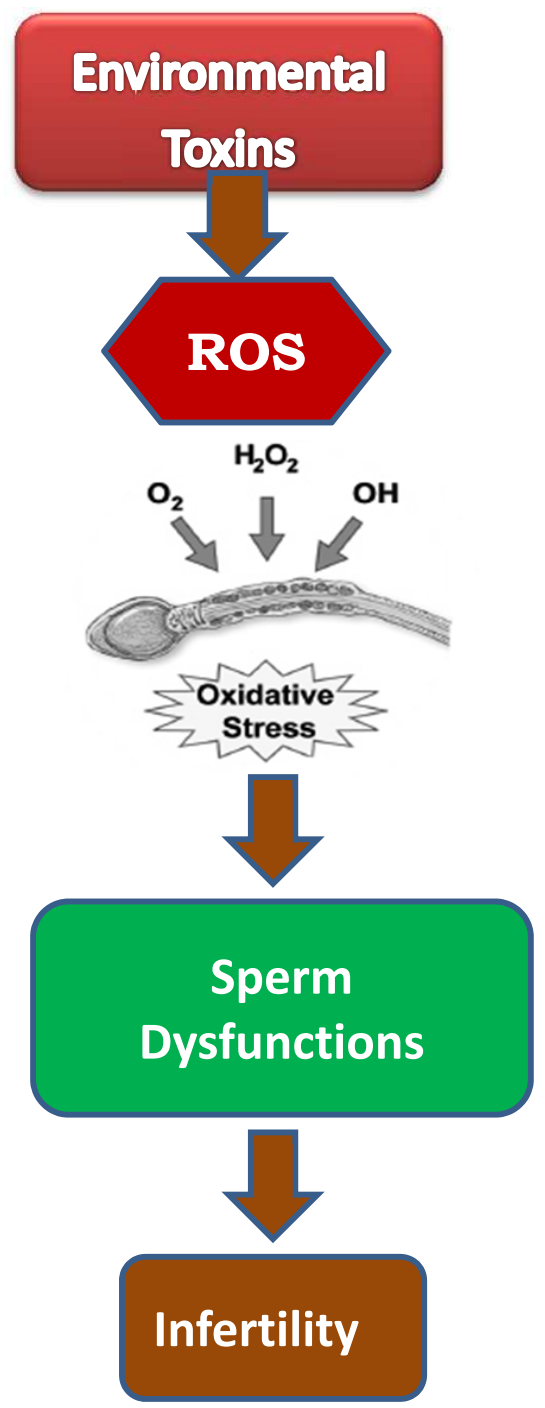

Fig. 5. Primary pathologies of male reproductive system in connection with environmental toxins, oxidative stress and infertility. 


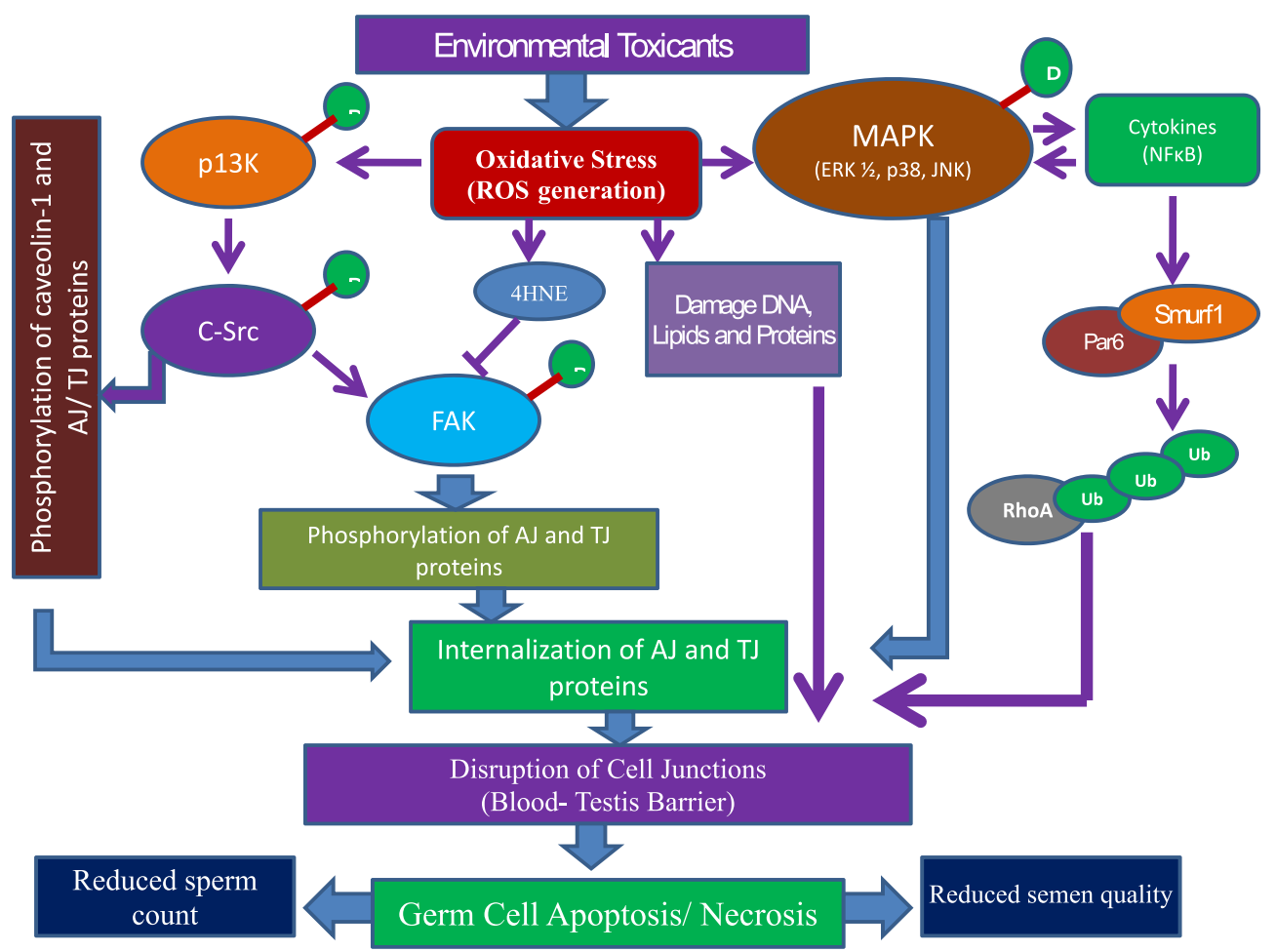

Fig. 6. Molecular signalling pathways of testicular toxicity by environmental toxicants through the induction of oxidative stress. Oxidative stress induced by environmental toxicants activates the PI3K/ C-src/FAK pathway, which subsequently controls the phosphorylation of TJ and/or AJ proteins. This leads to the internalization of TJ and AJ proteins at the cell-cell interface. In addition, environmental toxicants induce the production of cytokines which are also regulated by the activation of MAPK through oxidative stress. Cytokines stimulate the production of reactive oxygen species (ROS) from leukocytes to further increase oxidative stress. Cytokines and the activation of MAPK together result in endocytic vesicle- mediated internalization of TJ and AJ proteins. Polarity proteins such as Par6 are also involved in mediating the action of cytokines to recruit the E3 ubiquitin ligase Smurf1 for the poly ubiquitination and degradation of RhoA, which is important for the disruption of cell junctions. This illustrates that crosstalk exists between the PI3K/C$\mathrm{Src} / \mathrm{FAK}$ and cytokines/ MAPK pathways via polarity proteins as their common downstream signalling mediators. The disruption of cell junctions ultimately leads to the germ cell apoptosis and necrosis and as a result sperm count and quality of semen are reduced. (Modified from Wong \& Cheng, Trends in Pharmacological Sciences, 2011).

\section{Conclusions}

In view of the fact that the preliminary concerns arose about environmental chemicals or toxins and declining sperm counts, there has been an explosion of research in this area. The initial 'environmental oestrogen' hypothesis has been superseded by a more refined 
definition of EDCs. It is now accepted that there are a plethora of ways in which the environmental chemicals can potentially act on the endocrine as well as male reproductive systems. Though supportive data must need to determine whether human male reproductive health is declining or not. However; the hypothesis of a 'testicular dysgenesis syndrome' is an important advancement and may aid our understanding of the underlying aetiology of these disorders. Within the reproductive tract, the male is exquisitely vulnerable to the effects of anti-androgens during development due the dependence on the synthesis and action of androgens for the masculinization of the male reproductive tract. The ability of phthalates to suppress androgen synthesis during development and to induce testicular dysgenesis together with cryptorchidism and hypospadias has close parallels with human TDS. However, the crucial question regarding whether the level of environmental chemicals is sufficient to impact on human male reproductive health remains unanswered, although advances will be made from studying the effects of multi-component EDC mixtures in both in vitro and in vivo test systems. Moreover, it has been observed that in wildlife, there is a increasing rates of testicular cancer, to the debate regarding trends in sperm counts, there has been increasing concern that hazardous substances in the environment adversely affect male reproductive health. The ultimate benefits of this chapter that should serve as a framework for future studies to improve our knowledge in this area. By better defining the problems, learning about the mechanisms responsible for adverse effects, and developing panels of relevant biomarkers, we will make progress toward preventing future adverse effects on male reproductive health.

\section{Acknowledgment}

The authors acknowledge the financial support provided by the Bose Institute, Kolkata.

\section{References}

[1] Adami H.O., Bergstrom R., Mohner M., Zatonski W., Storm H., Ekbom A., Tretli S., Teppo L., Ziegler H. \& Rahu M. 1994. Testicular cancer in nine northern European countries. International Journal of Cancer, Vol 59, pp. 33-38.

[2] Adlercreutz, H., Höckerstedt, K., Bannwart, C., Bloigu, S., Hämäläinen, E., \& Fotsis, T. and Ollus, A. 1987. Effect of dietary components, including lignans and phytoestrogens, on enterohepatic circulation and liver metabolism of estrogens and on sex hormone binding globulin (SHBG). Journal of Steroid Biochemistry, Vol 27, pp.1135-1144.

[3] Almog, T. \& Naor, Z. 2010. The role of mitogen activated protein kinase (MAPK) in sperm functions. Molecular Cellular Endocrinology, Vol 314, pp.239-243.

[4] Akingbemi, B.T. 2005. Estrogen regulation of testicular function. Reproductive Biology and Endocrinology, Vol 3: pp. 51.

[5] Anderson RA., \& Sharpe RM. 2000. Regulation of inhibin production in the human male and its clinical applications. International Journal of Andrology, Vol. 23, pp.136-144.

[6] Anway, M.D., Cupp, A.S., Uzumcu, M. \& Skinner, M.K. 2005. Epigenetic transgenerational actions of endocrine disruptors and male fertility. Science, Vol. 308, pp. 1466-1469.

[7] Apostoli, P., Romeo, L., Peroni, E., Ferioli, A., Ferrari, S., Pasini, F., \& Aprili, F.1996. Steroid hormone sulphation in lead workers. British Journal of Industrial Medicine, Vol. 46, pp.204-208. 
[8] Atanassova, N., McKinnell, C., Walker, M., Turner, K. J., Fisher, J. S., Morley, M., Millar, M. R., Groome, N. P. \& Sharpe, R. M. 1999. Permanent effects of neonatal estrogen exposure in rats on reproductive hormone levels, Sertoli cell number, and the efficiency of spermatogenesis in adulthood. Endocrinology, Vol.140, pp. 5364-5373.

[9] Ayotte, P., Giroux, S., Dewailly, E., Hernandez Avila, M., Farias, R., Danis, P. \& Villanueva Diaz, C. 2001. DDT spraying for malaria control and reproductive function in Mexican men. Epidemiology. Vol. 12 pp. 366-367.

[10] Barlow, N. J., Phillips, S. L., Wallace, D. G., Sar, M., Gaido, K. W. \& Foster, P. M. 2003. Quantitative changes in gene expression in fetal rat testes following exposure to di(n-butyl) phthalate. Toxicological Sciences, Vol.73, pp. 431-441.

[11] Bergstrom R., Adami H.O., Mohner M., Zatonski W., Storm H., Ekbom A., Tretli S., Teppo L., Akre O. \& Hakulinen T. 1996. Increase in testicular cancer incidence in six European countries: a birth cohort phenomenon. Journal of the National Cancer Institute, Vol. 88, pp. 727-733.

[12] Benoff, S., Cooper, G.W., \& Hurley I, et al. 1994. The effect of calcium ion channel blockers on sperm fertilization potential. Fertility and Sterility. Vol. 62, pp. 606-617.

[13] Birnbaum, L. S. \& Tuomisto, J. 2000. Non-carcinogenic effects of TCDD in animals. Food Additives and Contaminants, Vol.17, pp. 275-288.

[14] Bracken, M.B., Eskenazi, B., Sachse, K., McSharry, J.E., Hellenbrand, K., \& LeoSummers, L. 1990. Association of cocaine use with sperm concentration, motility, and morphology. Fertility and Sterility. Vol. 53, pp. 315-322.

[15] Bozec, A., Chuzel, F., Chater, S., Paulin, C., Bars, R., Benahmed, M. \&Mauduit, C. 2004. The mitochondrial-dependent pathway is chronically affected in testicular germ cell death in adult rats exposed in utero to anti-androgens. Journal of Endocrinology, Vol.183, pp. 79-90.

[16] Braude, P. \& Rowell, P. 2003. Assisted conception. II-In vitro fertilisation and intracytoplasmic sperm injection. British Medical Journal, Vol. 327, pp. 852-855.

[17] Carlsen, E., Giwercman, A., Keiding, N. \& Skakkebaek. N.E. 1992. Evidence for decreasing quality of semen during past 50 years. British Medical Journal Vol. 305, pp. 609-613.

[18] Carreau, S. \& Hess, R.A. 2010. Oestrogens and spermatogenesis, Philos. Trans. R. Soc. Lond. B: Biol. Sci. Vol. 365, pp.1517-1535.

[19] Casini, M. L., Gerli, S. \& Unfer, V. 2006. An infertile couple suffering from oligospermia by partial sperm maturation arrest: can phytoestrogens play a therapeutic role? A case report study. Gynecological Endocrinology, Vol.22, pp. 399-401.

[20] Chapin, R.E., Sloane, R.A., \& Haseman, J.K. 1997. The relationships among reproductive endpoints in Swiss mice, using the reproductive assessment by continuous breeding database. Fundamental Applied Toxicology, Vol. 38, pp.129-142.

[21] Chen, L. et al., 2008. Cadmium activates the mitogen-activated protein kinase (MAPK) pathway via induction of reactive oxygen species and inhibition of protein phosphatases 2A and 5. Free Radical Biology and Medicine Vol.45, pp. 1035-1044.

[22] Clark, B. J., Wells, J., King, S.R. \& Stocco, D. M. 1994. The purification, cloning, and expression of a novel luteinizing hormone-induced mitochondrial protein in MA10 mouse Leydig tumor cells. Characterization of the steroidogenic acute regulatory protein (StAR). Journal of Biological Chemistry, Vol. 269, pp.28314-28322.

[23] Claudio, L., Bearer, C.F., \& Wallinga, D. 1999. Assessment of the U.S. Environmental Protection Agency methods for identification of hazards to developing organisms. Part I: the reproduction and fertility testing guidelines. American Journal of Industrial Medicine, Vol. 35, pp.543-553. 
[24] Close, C.E., Roberts, P.L., \& Berger, R.E. 1990. Cigarettes, alcohol and marijuana are related to pyospermia in infertile men. Journal of Urology. Vol. 144, pp. 900-903.

[25] Davies, J.M. 1981. Testicular cancer in England and Wales; some epidemiological aspects. Lancet Vol. 1(8226), pp.928-932.

[26] Dhanabalan, S. \& Mathur, P.P. 2009. Low dose of 2,3,7,8 tetrachlorodibenzo-p-dioxin induces testicular oxidative stress in adult rats under the influence of corticosterone, Experimental Toxicology and Pathology, Vol.61, pp. 415-423.

[27] Dhooge, W., van Larebeke, N., Koppen, G., Nelen, V., Schoeters, G., Vlietinck, R., Kaufman, J.-M. \& Comhaire, F. 2006. Serum dioxin-like activity is associated with reproductive parameters in young men from the general Flemish population. Environ. Health Perspect. , 114: 1670-1676.

[28] Ekbom, A., \& Akre, O. 1998. Increasing incidence of testicular cancer--birth cohort effects. Acta Pathologica, Microbiologica et Immunologica Scandinavica Vol.106, pp.225231.

[29] Evans, B. A., Griffiths, K. and Morton, M. S. 1995. Inhibition of 5 alpha-reductase in genital skin fibroblasts and prostate tissue by dietary lignans and isoflavonoids. Journal of Endocrinology, Vol.147, pp. 295-302.

[30] Fielden, M. R., Halgren, R. G., Fong, C. J., Staub, C., Johnson, L., Chou, K. \& Zacharewski, T. R. 2002. Gestational and lactational exposure of male mice to diethylstilbestrol causes long-term effects on the testis, sperm fertilizing ability in vitro, and testicular gene expression. Endocrinology, Vol.143, pp. 3044-3059.

[31] Fisch H., Andrews, H., Hendricks, J., Goluboff, E.T., Olson, J.H., \& Olsson, C.A. 1997. The relationship of sperm counts to birth rates: a population based study. Urology, Vol. 157, pp.840-844.

[32] Fisch, H., Goluboff, E.T., Olson, J.H., Feldshuh, J., Broder, S.J., \& Barad, D.H. 1996. Semen analyses in 1,283 men from the United States over a 25-year period: no decline in quality. Fertility and Sterility, Vol.65, pp.1009-1014.

[33] Fisher, J.S. 2004. Environmental anti-androgens and male reproductive health: focus on phthalates and testicular dysgenesis syndrome. Reproduction Vol. 127, pp. 305-315.

[34] Fisher, J. S., Macpherson, S., Marchetti, N. \& Sharpe, R. M. 2003. Human 'testicular dysgenesis syndrome': A possible model using in-utero exposure of the rat to dibutyl phthalate. Human Reproduction, Vol.18, pp. 1383-1394.

[35] Foster, P. M., Mylchreest, E., Gaido, K. W. \& Sar, M. 2001. Effects of phthalate esters on the developing reproductive tract of male rats. Human Reproduction Update , Vol. 7, pp. 231-235.

[36] Fredricsson, B., Moller, L., Pousette, A. \& Westerholm, R. 1993. Human sperm motility is affected by plasticizers and diesel particle extracts. Pharmacology $\mathcal{E}$ Toxicology, Vol. 72, pp. 128-133.

[37] Gray, L.E., Ostby, J., Furr, J., Wolf, C.J., Lambright, C., Parks, L., Veeramachaneni, D.N., Wilson, V., Price, M., Hotchkiss, A., Orlando, E. \& Guillette, L. 2001. Effects of Environmental Antiandrogens on Reproductive Development in Experimental Animals. Human Reproduction Update, Vol. 7, pp. 248-264.

[38] Gray, L.E., Ostby, J., Price, M., Veeramachaneni, D.N., \& Parks, L. 2000. Parinatal exposure to the pathalates DEHP, BBP and DIVD, but not DEP, BMP or DOTP alters sexual differentiation of the male rats. Toxicological Sciences, Vol. 58, pp. 350365.

[39] Gray, L.E., Wolf, C., Lambright, C., Mann, P., Price, M., Cooper, R. L. \& Ostby, J. 1999. Administration of potentially antiandrogenic pesticides (procymidone, linuron, iprodione, chlozolinate, $p, p^{\prime}$-DDE, and ketoconazole) and toxic substances (dibutyl- 
and diethylhexyl phthalate, PCB 169, and ethane dimethane sulphonate) during sexual differentiation produces diverse profiles of reproductive malformations in the male rat. Toxicology and Industrial Health, Vol.15, pp. 94-118.

[40] Ge, R. S., Chen, G. R., Tanrikut, C. \& Hardy, M. P. 2007. Phthalate ester toxicity in Leydig cells: Developmental timing and dosage considerations. Reproductive Toxicology, Vol.23, pp. 366-373.

[41] Guo, Y. L., Hsu, P. C., Hsu, C. C. \& Lambert, G. H. 2000. Semen quality after prenatal exposure to polychlorinated biphenyls and dibenzofurans. Lancet, Vol.356, pp. 1240-1241.

[42] Gupta, C. 2000. Reproductive malformation of the male offspring following maternal exposure to estrogenic chemicals. Proc. Soc. Exp. Biol. Med., Vol. 224, pp. 61-68.

[43] Haffner, S. M. 1996. Sex hormone-binding protein, hyper-insulinaemia, insulin resistance and noninsulindependent diabetes. Hormone Research, Vol.45, pp. 233237.

[44] Hargreaves, C.A., Rogers, S., Hills, F., Rahman, F., Howell, R.J. \& Homa, S.T. 1998. Effects of co-trimoxazole, erythromycin, amoxycillin, tetracycline and chloroquine on sperm function in vitro. Human Reproduction, vol. 13, pp. 1878-1886.

[45] Hauser, R. \& Sokol, R., 2008. Science linking environmental contaminant exposures with fertility and reproductive health impacts in the adult male, Fertilily and Sterility, Vol. 89: pp. e59-e65.

[46] Hauser, R., Williams, P., Altshul, L. \& Calafat, A. M. 2005. Evidence of interaction between polychlorinated biphenyls and phthalates in relation to human sperm motility. Environmental Health Perspectives, Vol.113, pp. 425-430.

[47] Hess, R. A., Bunick, D., Lee, K. H., Bahr, J., Taylor, J. A., Korach, K. S., \& Lubahn, D. B. 1997. A role for oestrogens in the male repro- ductive system. Nature. Vol.390, pp. 509-512.

[48] Isojarvi, J.I., Lofgren, E., \& Juntunen K.S., et al. 2004. Effect of epilepsy and antiepileptic drugs on male reproductive health. Neurology. Vol. 62, pp. 247-253.

[49] ILSI. 1999. An Evaluation and Interpretation of Reproductive Endpoints for Human Health Risk Assessment (Daston G, Kimmel C, eds), International Life Sciences Institute Press, Washington, DC.

[50] Jana, K., Jana, S., \& Samanta, P.K. 2006. Effects of chronic exposure to sodium arsenite on hypothalamo-pituitary-testicular activities in adult rats: possible an estrogenic mode of action. Reproductive Biology Endocrinology, Vol. 4: pp.9-22.

[51] Jana, K., Samanta, P.K., \& De, D.K. 2010a. Nicotine diminishes testicular gametogenesis, steroidogenesis and steroidogenic acute regulatory protein expression in adult albino rats: possible influence on pituitary gonadotropins and alteration of testicular antioxidant status. Toxicological Sciences, vol.116, pp. 647-59.

[52] Jana, K., Yin, X., Schiffer, R.B., Chen, J-J., Pandey, A.K., Stocco, D.M., Grammas, P., \& Wang, X. 2008. Chrysin, a natural flavonoid enhances steroidogenesis and steroidogenic acute regulatory protein gene expression in mouse Leydig cells. Journal of Endocrinology, vol.197, pp. 315-323.

[53] Jana, K., Jana, N., De, D.K., \& Guha, S.K. 2010b. Eathanol induces mouse spermatogenic cell apoptosis in vivo through overexpression of Fas/Fas-L, p53, and caspase-3 along with cytochrome-c translocation and glutathione depletion. Molecular Reproduction E Development, vol. 77, pp. 820-833.

[54] Jensen, M. S., Mabeck, L. M., Toft, G., Thulstrup, A. M. \& Bonde, J.P. 2005. Lower sperm counts following prenatal tobacco exposure. Human Reproduction, vol. 20, pp. 25598566 . 
[55] Kabuto, H. et al., 2004. Exposure to bisphenol A during embryonic/fetal life and infancy increases oxidative injury and causes underdevelopment of the brain and testis in mice, Life Sciences, Vol. 74, pp. 2931-2940.

[56] Kelce, W. R., Stone, C. R., Laws, S. C., Gray, L. E., Kemppainen, J. A. \& Wilson, E. M. 1995. Persistent DDT metabolite $\mathrm{p}, \mathrm{p}^{\prime}$-DDE is a potent androgen receptor antagonist. Nature, vol. 375, pp. 581-585.

[57] Khorram, O., Garthwaite, M., Jones, J. \& Golos, T. 2004. Expression of aryl hydrocarbon receptor (AHR) and aryl hydrocarbon receptor nuclear translocator (ARNT) mRNA expression in human spermatozoa. Med. Sci. Monit., vol. 10, pp. 135-138.

[58] Khoury, M.J., \& Dorman, J.S. 1998. The human genome epidemiology network. American Journal of Epidemiology, vol.148, pp.1-3.

[59] Khoury, M.J. 1997. Genetic epidemiology and the future of disease prevention and public health. Epidemiologic Reviews, Vol. 19, pp.175-180.

[60] Kizu, R., Okamura, K., Toriba, A., Kakishima, H., Mizokami, A., Burnstein, K. L. \& Hayakawa, K. 2003. A role of aryl hydrocarbon receptor in the antiandrogenic effects of polycyclic aromatic hydrocarbons in $\mathrm{LNCaP}$ human prostate carcinoma cells. Archies of Toxicology, vol. 77, pp. 335-343.

[61] Kuiper, G. G., Lemmen, J. G., Carlsson, B., Corton, J. C., Safe, S. H., van der Saag, P. T., van der Burg, B., \& Gustafsson, J. A. 1998. Interaction of estrogenic chemicals and phytoestrogens with estrogen receptor beta. Endocrinology vol. 139, pp. 4252-4263.

[62] Latchoumycandane, C. \& Mathur, P.P. 2002. Effects of vitamin E on reactive oxygen species-mediated 2,3,7,8-tetrachlorodi-benzo-p-dioxin toxicity in rat testis, Journal of Applied Toxicology, vol. 22, pp. 345-351.

[63] Lawson, C.C., Schnorr, T.M., Daston, G.P., Grajewski, B., Marcus, M., \& McDiarmid, M. et al., 2003. An Occupational Reproductive Research Agenda for the Third Millennium. Environmental Health Perspectives, vol.111, pp. 584-592.

[64] Lecureur, V. et al., 2005. ERK-dependent induction of TNFalpha expression by the environmental contaminant benzo(a)pyrene in primary human macrophages, FEBS Letters, vol. 579, pp. 1904-1910.

[65] Li, M.W.M. et al., 2006. Tumor necrosis factor \{alpha\} reversibly disrupts the bloodtestis barrier and impairs Sertoli-germ cell adhesion in the seminiferous epithelium of adult rat testes, Journal of Endocrinology, vol.190, pp. 313-329.

[66] Li, M.W.M., Murk, D.D., \& Cheng, C.Y. 2009. Mitogen-activated protein kinases in male reproductive function. Trends in Molecular Medicine, vol. 15, pp. 159-168.

[67] Liu, J. et al., 2009. Role of oxidative stress in cadmium toxicity and carcinogenesis, Toxicology and Applied Pharmacology, vol. 238, pp. 209-214.

[68] Maire, M., Florin, A., Kaszas, K., Regnier, D., Contard, P., Tabone, E., Mauduit, C., Bars, R. \& Benahmed, M. 2005. Alteration of transforming growth factor-beta signaling system expression in adult rat germ cells with a chronic apoptotic cell death process after fetal androgen disruption. Endocrinology, Vol. 146, pp. 5135-5143.

[69] Magelssen, H., Brydoy, M. \& Fossa, S.D. 2006. The effects of cancer and cancer treatments on male reproductive function. Nat Clin Pract Urol. Vol. 3, pp. 312-322.

[70] Martin, R.H., Ernst, S., Rademaker, A., Barclay, L., Ko, E., \& Summers, N. 1997. Chromosomal abnormalities in sperm from testicular cancer patients before and after chemotherapy. Human Genetics, vol. 99, pp.214-218.

[71] McIntyre, B.S., Barlow, N.J. \& Foster, P.M. 2002. Male rats exposed to linuron in utero exhibit permanent changes in anogenital distance, nipple retention, and epididymal malformations that result in subsequent testicular atrophy. Toxicological Sciences, vol. 65, pp. 62-70. 
[72] McKinnell, C., Atanassova, N., Williams, K., Fisher, J.S., Walker, M., Turner, K.J., Saunders, T.K. \& Sharpe, R.M. 2001. Suppression of androgen action and the induction of gross abnormalities of the reproductive tract in male rats treated neonatally with diethylstilbestrol. Journal of Andrology, vol. 22, pp. 323-338.

[73] McKinney, J.D. \& Waller, C.L. 1998. Molecular determinants of hormone mimicry: Halogenated aromatic hydrocarbon environmental agents. Journal of Toxicology and Environmental Health B, Vol.1, pp. 27-58.

[74] Meeker, J.D., Ryan, L., Barr, D.B., Herrick, R.F., Bennett, D.H., Bravo, R. \& Hauser, R. 2004. The relationship of urinary metabolites of carbaryl/naphthalene and chlorpyrifos with human semen quality. Environmental Health Perspectives, vol. 112, pp. 1665-1670.

[75] Miller, W.L. 1988. Molecular biology of steroid hormone synthesis. Endocrine Reviews , vol. 9, pp. 295-318.

[76] Mitchell, J.H., Cawood, E., Kinniburgh, D., Provan, A., Collins, A. R. \& Irvine, D. S. 2001. Effect of a phytoestrogen food supplement on reproductive health in normal males. Clinical Science (Lond.), vol. 100, pp. 613-618.

[77] Moline, J.M., Golden, A., Bar-Chama, N., Smith, E., Rauch, M.E., \& Chapin RE, et al., 2000. Exposure to hazardous substances and male reproductive health: a research framework. Environmental Health Perspectives, vol. 108, pp.803-813.

[78] Moorman, W.J., Ahlers, H.W., Chapin, R.E., Daston, G.P., Foster, P.M.D., \& Kavlock, R.J., et al., 2000. Prioritization of NTP reproductive toxicants for field studies. Reproductive Toxicology, vol. 14, pp. 293-301.

[79] Moosani, N., Pattinson, H.A., Carter, M.D., Cox, D.M., Rademaker, A.W., \& Martin, R.H. 1995. Chromosomal analysis of sperm from men with idiopathic infertility using sperm karyotyping and fluorescence in situ hybridization. Fertility and Sterility, vol. 64, pp. 811-817.

[80] Mylchreest, E., Wallace, D. G., Cattley, R. C. \& Foster, P. M. 2000. Dose-dependent alterations in androgen-regulated male reproductive development in rats exposed to di(n-butyl). Toxicological Sciences, vol. 55, pp. 143-151.

[81] NIOSH. 1978. National Occupational Hazards Survey. Vol III. Survey Analysis and Supplemental Tables. DHHS (NIOSH) Publication no. 78-114, National Institute for Occupational Safety and Health, Cincinnati, $\mathrm{OH}$.

[82] NIOSH. 1988. National Occupational Exposure Survey Analysis of Management Interview Responses. DHHS (NIOSH) Publ no. 89-103, National Institute for Occupational Safety and Health, Cincinnati, $\mathrm{OH}$.

[83] O'Donnell, L., Robertson, K. M., Jones, M. E. \& Simpson, E. R. 2001. Estrogen and spermatogenesis. Endocrinine Reviews, vol. 22, pp. 289-318.

[84] Overstreet, J.W., Fuh, V.L., \& Gould, J. et al. 1999. Chronic treatment with finasteride daily does not affect spermatogenesis or semen production in young men. Journal of Urology, vol. 162, pp.1295-1300.

[85] Nudell, D.M., Monoski, M.M. \& Lipshultz, L.I. 2002. Common medications and drugs: how they affect male fertility. Urol Clin North Am. Vol. 29, pp. 965-973.

[86] Pant, N., Mathur, N., Banerjee, A.K., Srivastava, S. P. \& Saxena, D.K. 2004. Correlation of chlorinated pesticides concentration in semen with seminal vesicle and prostatic markers. Reproductive Toxicology, vol. 19, pp. 209-214.

[87] Park, J.D., Habeebu, S.S. \& Klaassen, C.D. 2002. Testicular toxicity of di-(2ethylhexyl)phthalate in young Sprague-Dawley rats. Toxicology, vol. 171, pp. 105115. 
[88] Parks, L.G., Ostby, J.S., Lambright, C.R., Abbott, B.D., Klinefelter, G.R., Barlow, N.J. \& Gray, L.E. Jr. 2000. The plasticizer diethylhexyl phthalate induces malformations by decreasing fetal testosterone synthesis during sexual differentiation in the male rat. Toxicological Sciences, vol. 58, pp. 339-349.

[89] Peltola, V., Mantyla, E., Huhtaniemi, I. \& Ahotupa, M. 1994. Lipid peroxidation and antioxidant enzyme activities in the rat testis after cigarette smoke inhalation or administration of polychlorinated biphenyls or polychlorinated naphthalenes. Journal of Andrology, vol. 15, pp. 353-361.

[90] Peterson, R.E., Theobald, H.M. \& Kimmel, G.L. 1993. Developmental and reproductive toxicity of dioxins and related compounds: Cross-species comparisons. Critical Reviews in Toxicology, vol. 23, pp. 283-335.

[91] Phillips, K.P. \& Tanphaichitr N. 2008. Human exposure to endocrine disrupters and semen quality, Journal of Toxicology and Environmental Health Part B. vol. 11, pp. 188220

[92] Pryor, J.L., Hughes, C., Foster, W., Hales, B.F., \& Robaire, B. 2000. Critical windows of exposure for children's health: The reproduc- tive system in ani mals and humans. Environmental Health Perspectives, vol. 108, pp. 491-503.

[93] Purvis, K., Magnus, O., Morkas, L., Abyholm, T., \& Rui, H. 1986. Ejaculate composition after masturbation and coitus in the human male. International Journal of Andrology, vol. 9, pp. 401-406.

[94] Qureshi, M.S., Pennington, J.H., Goldsmith, H.J., \& Cox, P.E. 1972. Cyclophosphamide therapy and sterility. Lancet, vol. 16, pp. 1290-1291.

[95] Rajpert-De Meyts, E., Bartkova, J., Samson, M., Hoei-Hansen, C.E., Frydelund-Larsen, L., Bartek, J. \& Skakkebaek, N.E. 2003. The emerging phenotype of the testicular carcinoma in situ germ cell. Acta Pathologica, Microbiologica et Immunologica Scandinavica, vol. 111, pp. 267-278.

[96] Ramlau-Hansen, C.H., Thulstrup, A. ., Aggerholm, A.S., Jensen, M.S., Toft, G. \& Bonde, J. P. 2007. Is smoking a risk factor for decreased semen quality? A cross-sectional analysis. Human Reproduction, vol. 22, pp. 188-196.

[97] Richardson, D.B., \& Wing, S. 1998. Methods for investigating age differences in the effects of prolonged exposures. American Journal of Industrial Medicine, vol. 33, pp.123-130.

[98] Rivas, A., Fisher, J.S., McKinnell, C., Atanassova, N. \& Sharpe, R.M. 2002. Induction of reproductive tract developmental abnormalities in the male rat by lowering androgen production or action in combination with a low dose of diethylstilbestrol: evidence for importance of the androgen-estrogen balance. Endocrinology, vol. 143, pp. 4797-4808.

[99] Robbins, W.A., Vine, M.F., Truong, K.Y. \& Everson, R.B. 1997. Use of FISH (fluorescence in situ hybridization) to assess effects of smoking, caffeine, and alcohol on aneuploidy load in sperm of healthy men. Environmental Molecular Mutagenesis, vol. 30, pp. 175-183.

[100] Roy, D., Palangat, M., Chen, C.W., Thomas, R.D., Colerangle, J., Atkinson, A., and Yan, Z.J. 1997. Biochemical and molecular changes at the cellular level in response to exposure to environmental estrogen-like chemicals. Journal of Toxicology and Environmental Health, vol. 50, pp.1-29.

[101] Rozati, R., Reddy, P.P., Reddanna, P. \& Mujtaba, R. 2002. Role of environmental estrogens in the deterioration of male factor fertility. Fertility and Sterility, vol. 78, pp. 1187-1194. 
[102] Ryu, J.Y., Whang, J., Park, H., Im, J. Y., Kim, J., Ahn, M. Y., Lee, J., Kim, H. S., Lee, B. M., Yoo, S.D., Kwack, S. J., Oh, J. H., Park, K. L., Han, S. Y. \& Kim, S.H. 2007. Di(2ethylhexyl) phthalate induces apoptosis through peroxisome proliferatorsactivated receptor-gamma and ERK $1 / 2$ activation in testis of Sprague-Dawley rats. Journal of Toxicology and Environmental Health part A, vol. 70, pp. 1296-1303.

[103] Sanderson, J.T., Seinen, W., Giesy, J.P. \& van den Berg, M. 2000. 2-Chloro-s-triazine herbicides induce aromatase (CYP19) activity in H295R human adrenocortical carcinoma cells: A novel mechanism for estrogenicity?. Toxicological Sciences, vol. 54: pp. 121-127.

[104] Sandoval, K.E. \& Witt, K.A. 2008. Blood-brain barrier tight junction permeability and ischemic stroke. Neurobiology of Disease, vol. 32, pp. 200-219.

[105] Schrader SM. 1997. Male reproductive toxicity. In: Handbook of Human Toxicology (Massaro EJ, ed). pp. 962-980, CRC Press, Boca Raton, FL.

[106] Schlegel, P.N., Chang, T.S. \& Marshall, F.F. 1991. Antibiotics: potential hazards to male fertility. Fertility and Sterility, vol. 55, pp. 235-242.

[107] Seed, J., Chapin, R.E., Clegg, E.D., Dostal, L.A., Foote, R.H., \& Hurtt, M.E., et al., 1996. Methods for assessing sperm motility, morphology, and counts in the rat, rabbit, and dog: a consensus report. Reproductive Toxicology, vol. 10, pp. 237-244.

[108] Sharpe, R.M., \& Irvine, D.S. 2004. How strong is the evidence of a link between environmental chemicals and adverse effects on human reproductive health. BMJ,. vol. 328, pp. 447-451.

[109] Sharpe RM \& Franks S. 2002. Environment, lifestyle and infertility - an intergenerational issue. Nature Cell Biology 4, (Suppl) S33-S40.

[110] Sharpe, R.M. 2003. The 'oestrogen hypothesis' - where do we stand now? International Journal of Andrology, vol. 26, pp. 2-15.

[111] Sharpe, R.M. 2010. Environmental/lifestyle effects on spermatogenesis. Phil. Trans. R. Soc. B., vol. 365, pp. 1697- 1712.

[112] Sharpe, R.M., \& Skakkebaek, N.E. 1993. Are oestrogens involved in falling sperm counts and disorders of the male reproductive tract? Lancet, vol. 29, pp. 1392-1395.

[113] Sikka, S.C. 2001. Relative impact of oxidative stress on male reproductive function, Current Medicinal Chemistry, vol. 8, pp. 851-862.

[114] Skakkebaek, N.E., Holm, M., Hoei-Hansen, C., Jorgensen, N. \& Rajpert-De Meyts, E. 2003. Association between testicular dysgenesis syndrome (TDS) and testicular neoplasia: evidence from 20 adult patients with signs of maldevelopment of the testis. Acta Pathologica, Microbiologica et Immunologica Scandinavica, vol. 111, pp. 1-9.

[115] Skakkebaek, N.E., Rajpert-De Meyts, E. \& Main, K.M. 2001. Testicular dysgenesis syndrome: an increasingly common developmental disorder with environmental aspects. Human Reproduction, vol. 16, pp. 972-978.

[116] Stillman, R.J. 1982. In utero exposure to diethylstilbestrol: adverse effects on the reproductive tract and reproductive performance and male and female offspring. American Journal of Obstetrics and Gynecology, vol. 142, pp. 905-921.

[117] Stone, R. 2007. Epidemiology. Agent Orange's bitter harvest. Science, vol. 315, pp. 176179.

[118] Strauss, L., Santti, R., Saarinen, N., Streng, T., Joshi, S. \& Makela, S. 1998. Dietary phytoestrogens and their role in hormonally dependent disease. Toxicology Letters, vol. 102-103, pp. 349-354.

[119] Swan, S.H., Elkin, E.P., \& Fenster, L. 1997. Have sperm densities declined? A reanalysis of global trend data. Environmental Health Perspectives, vol. 105, pp. 12281232. 
[120] Swan, S.H. 2006. Semen quality in fertile US men in relation to geographical area and pesticide exposure. International Journal of Andrology, vol. 29, pp. 62-68.

[121] Swan, S.H., Kruse, R.L., Liu, F., Barr, D.B., Drobnis, E.Z., Redmon, J.B., Wang, C., Brazil, C., Overstreet, J.W. \& Study for Future Families Research Group. 2003. Semen quality in relation to biomarkers of pesticide exposure. Environmental Health Perspective, vol. 111, pp. 1478-1484.

[122] Tong, W., Perkins, R., Sterlitz, R., Collantes, E.R., Keenan, S., \& Welsh, W.J., et al.,1997. Quantitative structure-activity relationships (QSARs) for estrogen binding to the estrogen receptor: predictions across species. Environmental Health Perspectives, vol. 105, pp. 1116-1124.

[123] Toppari, J., Larsen, J.C., Christiansen, P., Giwercman, A., Grandjean, P., Guillett, L.J. Jr., et al., 1996. Male reproductive health and environmental xenoestrogens. Environmental Health Perspectives, vol. 104 (Suppl 4), pp. 741-803.

[124] Tremellen, K. 2008. Oxidative stress and male infertility - a clinical perspective, Human Reproduction Update, vol. 14, pp. 243-258.

[125] Tsai-Morris, C.H., Knox, G., Luna, S. \& Dufau, M.L. 1986. Acquisition of estradiolmediated regulatory mechanism of steroidogenesis in cultured fetal rat Leydig cells. Journal of Biological Chemistry, vol. 261, pp. 3471-3474.

[126] Toyoshiba, H., Yamanaka, T., Sone, H., Parham, F. M., Walker, N. J., Martinez, J. \& Portier, C.J. 2004. Gene interaction network suggests dioxin induces a significant linkage between aryl hydrocarbon receptor and retinoic acid receptor beta. Environmental Health Perspectives, vol. 112, pp. 1217-1224.

[127] Turner, T.T. \& Lysiak, J.J. 2008. Oxidative stress: a common factor in testicular dysfunction, Journal of Androl, vol. 29, pp. 488-498.

[128] U.S. EPA. 1998a. Health Effect Test Guidelines. Reproduction and Fertility Effects. OPPTS 870.3800, U.S. Environmental Protection Agency, Washington DC.

[129] U.S. EPA. 1998b. Endocrine Disruptor Screening and Testing Advisory Committee (EDSTAC); Final Report. U.S. EPA, Washington, DC.

[130] Vine, M.F. 1996. Smoking and male reproduction: A review. International Journal of Andrology, vol. 19, pp. 323-337.

[131] Walker, W.H., \& Cheng, J. 2005. FSH and testosterone signaling in Sertoli cells. Reproduction, vol. 130, pp.15-28.

[132] Whelan EA, Grajewski B, Wild DK, Schnorr TM, \& Alderfer R. 1996. Evaluation of reproductive function among men occupationally exposed to a stilbene derivative. II. Perceived libido and potency. American Journal of Industrial Medicine, vol. 29, pp.59-65.

[133] Whitten, P.L. \& Naftolin, F. 1998. Reproductive actions of phytoestrogens. Bail. Clin. Endocrinol. Metab. , vol. 12, pp. 667-690.

[134] Wilcox, A.J., Baird, D.D., Weinberg, C.R., Hornsby, P.P. \& Herbst, A.L. 1995. Fertility in men exposed prenatally to diethylstilbestrol. New England Journal of Meicine. Vol. 332, pp. 1411-1416.

[135] Whorton, D., Krauss, R.M., Marshall, S., \& Milby, T.H. 1977. Infertility in male pesticide workers. Lancet, vol. 2, pp. 1259-1261.

[136] Wolf, C.J., LeBlanc, G.A., Ostby, J.S. \& Gray, L.E. Jr. 2000. Characterization of the period of sensitivity of fetal male sexual development to vinclozolin. Toxicological Sciences, vol. 55, pp.152-161.

[137] Wong C.H. \& Cheng, C.Y. 2005. Mitogen-activated protein kinases, adherens junction dynamics, and spermatogenesis: A review of recent data. Developmental Biology, vol. 286, pp. 1-15. 
[138] Wong, C.H., Murk, D.D., Lui, W.Y., \& Cheng, C.Y. 2004. Regulation of blood-testis barrier dynamics: an in vivo study. Journal of Cell Sciences, vol. 117, pp. 783-798.

[139] Wong, E.W.P. \& Cheng, C.Y. 2011. Impacts of environmental toxicants on male reproductive dysfunction. Trends in Pharmacological Sciences, vol. 32, pp. 290-299.

[140] Wong, C., Kelce, W.R., Sar, M. \& Wilson, E.M. 1995. Androgen receptor antagonist versus agonist activities of the fungicide vinclozolin relative to hydroxyflutamide. Journal of Biological Chemistry, vol. 270, pp. 19998-20003.

[141] Woodruff, T.J., Carlson, A., Schwartz, J.M., \& Giudice, L.C. 2008. Proceedings of the sumit on environmental challenges to reproductive health and fertility: executive summary. Fertility and Sterility, vol. 89, pp. 281-300.

[142] World Health Organization (WHO). 1999. WHO laboratory manual for the examination of human sperm and semen-cervical mucus interaction, 4th ed, Cambridge University Press, Cambridge, NY.

[143] Wozniak, A.L., Bulayeva, N.N. \& Watson, C.S. 2005. Xenoestrogens at picomolar to nanomolar concentrations trigger membrane estrogen receptor-a-mediated $\mathrm{Ca}++$ fluxes and prolactin release in GH3/B6 pituitary tumor cells. Environmental Health Perspectives, vol. 113, pp. 431-439.

[144] Wyrobeck, A.J., Schrader, S.M., Perreault, S.D., Fenster, L., Huszar, G., Katz, D.F., Osorio, A.M., Sublet, V., \& Evenson, D. 1997. Assessment of reproductive disorders and birth defects in communities near hazardous chemical sites. III: Guidelines for field studies of male reproductive disorders. Reproductive Toxicology, vol. 11, pp. 243-259.

[145] You, L., Casanova, M., Archibeque-Engle, S., Sar, M., Fan, L.Q. \& Heck, H.A. 1998. Impaired male sexual development in perinatal Sprague-Dawley and Long-Evans hooded rats exposed in utero and lactationally to $\mathrm{p}^{\mathrm{p}} \mathrm{p}^{\prime}-\mathrm{DDE}$. Toxicological Sciences, vol. 45, pp.162-173.

[146] Zinaman, M.J., Brown, C.C., Selevan, S.G., \& Clegg, E.D. 2000. Semen quality and human fertility: a prospective study with healthy couples. Journal of Andrology, vol. 21, pp. 145-153. 


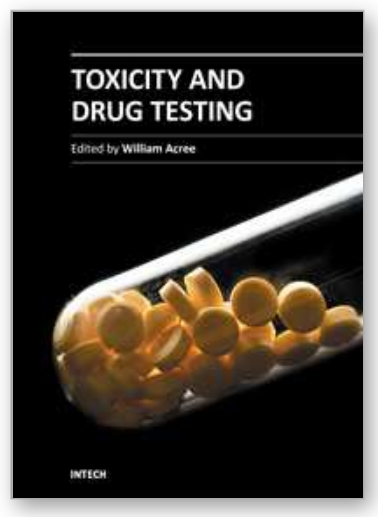

\author{
Toxicity and Drug Testing \\ Edited by Prof. Bill Acree
}

ISBN 978-953-51-0004-1

Hard cover, 528 pages

Publisher InTech

Published online 10, February, 2012

Published in print edition February, 2012

Modern drug design and testing involves experimental in vivo and in vitro measurement of the drug candidate's ADMET (adsorption, distribution, metabolism, elimination and toxicity) properties in the early stages of drug discovery. Only a small percentage of the proposed drug candidates receive government approval and reach the market place. Unfavorable pharmacokinetic properties, poor bioavailability and efficacy, low solubility, adverse side effects and toxicity concerns account for many of the drug failures encountered in the pharmaceutical industry. Authors from several countries have contributed chapters detailing regulatory policies, pharmaceutical concerns and clinical practices in their respective countries with the expectation that the open exchange of scientific results and ideas presented in this book will lead to improved pharmaceutical products.

\title{
How to reference
}

In order to correctly reference this scholarly work, feel free to copy and paste the following:

Kuladip Jana and Parimal C. Sen (2012). Environmental Toxicants Induced Male Reproductive Disorders: Identification and Mechanism of Action, Toxicity and Drug Testing, Prof. Bill Acree (Ed.), ISBN: 978-953-510004-1, InTech, Available from: http://www.intechopen.com/books/toxicity-and-drug-testing/environmentaltoxicants-induced-male-reproductive-disorders-identification-and-mechanism-of-action-

\section{INTECH}

open science | open minds

\author{
InTech Europe \\ University Campus STeP Ri \\ Slavka Krautzeka 83/A \\ 51000 Rijeka, Croatia \\ Phone: +385 (51) 770447 \\ Fax: +385 (51) 686166 \\ www.intechopen.com
}

\author{
InTech China \\ Unit 405, Office Block, Hotel Equatorial Shanghai \\ No.65, Yan An Road (West), Shanghai, 200040, China \\ 中国上海市延安西路65号上海国际贵都大饭店办公楼 405 单元 \\ Phone: +86-21-62489820 \\ Fax: +86-21-62489821
}


(C) 2012 The Author(s). Licensee IntechOpen. This is an open access article distributed under the terms of the Creative Commons Attribution 3.0 License, which permits unrestricted use, distribution, and reproduction in any medium, provided the original work is properly cited. 